University of South Carolina

Scholar Commons

$5-1-2001$

\title{
Oxygen Permeation Through Cobalt-Containing Perovskites: Surface Oxygen Exchange vs. Lattice Oxygen Diffusion
}

\author{
Kevin Huang \\ University of South Carolina - Columbia, huang46@cec.sc.edu \\ John B. Goodenough
}

Follow this and additional works at: https://scholarcommons.sc.edu/emec_facpub

Part of the Mechanical Engineering Commons

\author{
Publication Info \\ Published in Journal of The Electrochemical Society, Volume 148, Issue 5, 2001, pages E203-E214. \\ (C) Journal of The Electrochemical Society 2001, The Electrochemical Society. \\ (C) The Electrochemical Society, Inc. 2001. All rights reserved. Except as provided under U.S. copyright law, \\ this work may not be reproduced, resold, distributed, or modified without the express permission of The \\ Electrochemical Society (ECS). The archival version of this work was published in Journal of The \\ Electrochemical Society. \\ Publisher's Version: http://dx.doi.org/10.1149/1.1362548 \\ Huang, K. \& Goodenough, J. B. (2001). Oxygen Permeation Through Cobalt-Containing Perovskites: \\ Surface Oxygen Exchange vs. Lattice Oxygen Diffusion. Journal of The Electrochemical Society, 148 (5), \\ E203-E214. http://dx.doi.org/10.1149/1.1362548
}

This Article is brought to you by the Mechanical Engineering, Department of at Scholar Commons. It has been accepted for inclusion in Faculty Publications by an authorized administrator of Scholar Commons. For more information, please contact digres@mailbox.sc.edu. 


\title{
Oxygen Permeation Through Cobalt-Containing Perovskites
}

\section{Surface Oxygen Exchange vs. Lattice Oxygen Diffusion}

\author{
Keqin Huang, ${ }^{\mathrm{a}, *, \mathrm{z}}$ and John B. Goodenough
}

Texas Materials Institute, The University of Texas at Austin, Austin, Texas 78712, USA

\begin{abstract}
The oxygen permeation fluxes from $p_{\mathrm{O}_{2}}^{\prime}$ to $p_{\mathrm{O}_{2}}^{\prime \prime}\left(p_{\mathrm{O}_{2}}^{\prime}>p_{\mathrm{O}_{2}}^{\prime \prime}\right)$ across cobalt-containing perovskite ceramic membranes $\mathrm{La}_{1-x} \mathrm{Sr}_{x} \mathrm{CoO}_{3-\delta}$ and $\mathrm{SrCo}_{0.8} \mathrm{Fe}_{0.2} \mathrm{O}_{3-\delta}$ were measured by gas chromatography as functions of oxygen chemical potential gradient, temperature, thickness, and catalytic activity on the surface. Power indexes $0.5>n>0$ for uncatalyzed $\mathrm{La}_{1-x} \mathrm{Sr}_{x} \mathrm{CoO}_{3-\delta}$ and $1>n>0.5$ for $\mathrm{SrCo}_{0.8} \mathrm{Fe}_{0.2} \mathrm{O}_{3-\delta}$ were obtained when $J_{\mathrm{O}_{2}}$ vs. $p_{\mathrm{O}_{2}}^{\prime \text { n }}-p_{\mathrm{O}_{2}}^{\prime \prime n}$ was plotted as a straight line. The results clearly indicate an overall permeation process controlled by both surface oxygen exchange and bulk oxygen diffusion for uncatalyzed $\mathrm{La}_{1-x} \mathrm{Sr}_{x} \mathrm{CoO}_{3-\delta}$ and $\mathrm{SrCo}_{0.8} \mathrm{Fe}_{0.2} \mathrm{O}_{3-\delta}$. Application of a thin layer of catalytically active $\mathrm{SrCo}_{0.8} \mathrm{Fe}_{0.2} \mathrm{O}_{3-\delta}$ on the feeding-gas surface of $\mathrm{La}_{0.5} \mathrm{Sr}_{0.5} \mathrm{CoO}_{3-\delta}$ under the condition of a fixed $p_{\mathrm{O}_{2}}^{\prime}=0.21$ atm and a varied $p_{\mathrm{O}_{2}}^{\prime \prime}$ not only increases remarkably the overall oxygen flux, but also changes a mixed control to a bulk diffusion control. This enables evaluation of the bulk transport properties of the mixed conductors. A coat of $\mathrm{SrCo}_{0.8} \mathrm{Fe}_{0.2} \mathrm{O}_{3-\delta}$ on the permeate side has little catalytic effect, especially at low $p_{\mathrm{O}_{2}}^{\prime \prime}$ range, due to the formation of a poorly conducting brownmillerite phase. The results explicitly show a higher activation energy for the surface exchange kinetics than for the ambipolar transport in the mixed conductors. The mechanism of the surface exchange is discussed, and an analytic expression that agrees well with the experimental results is obtained.

(c) 2001 The Electrochemical Society. [DOI: 10.1149/1.1362548] All rights reserved.
\end{abstract}

Manuscript submitted May 18, 2000; revised manuscript received January 20, 2001.

Dense ceramic membranes exhibiting a high electronic and oxide-ion conductivity have attracted increasing attention in recent years since eventual commercialization of the chemical reactors based on these membranes provides an economic, clean, and efficient means to separate oxygen from ambient air or other oxygencontaining atmospheres. The success of this technology could possibly revolutionize the present chemical industry that manufactures the oxygen and synthetic gas $\left(\mathrm{H}_{2}+\mathrm{CO}\right)$ expensively. Theoretically, mixed electronic and oxide-ion conduction is an important transport phenomenon in oxide systems. A profound understanding of the transport mechanisms not only helps to establish physical models for practical oxygen reactors, but also provides criteria to find new families of mixed electronic and oxide-ion conductors.

Determination of oxide-ion conductivity in mixed conducting oxides is critical to a fundamental understanding of these materials. However, most promising mixed conductors, such as those with perovskite structure, possess a dominant electronic conductivity with a small component of oxide-ion conductivity. Therefore, a simple van der Pauw four-probe method only reveals the electronic conductivity because the oxygen flux is too small to be measured. Although numerous studies ${ }^{1-3}$ have made considerable effort to separate oxide-ion conductivity by ion-blocking and/or electronblocking methods, the experimental procedure appears to be complicated and the data lack reliability and reproducibility.

Maier ${ }^{4}$ has summarized three basic methods for studying oxideion transport in the oxide systems: electrical, isotope tracer, and chemical-gradient measurements. In the electrical measurement, represented by the van der Pauw method, an external electrical field $(\nabla \phi)$ is applied across the sample as a driving force. The internal electronic and/or oxide-ion current is balanced by an external electronic current, and Ohm's law prevails. The resulting conductivity thereby includes both electronic and/or oxide-ion conductivity. However, it is very difficult to separate a small fraction of oxide-ion conductivity from an electronically dominated total conductivity within the tolerance of experimental error. In this case, the measurement provides primarily information on the electrons. In the isotopetracer measurement, the surface of the sample is exposed to an atmosphere containing an isotope of oxygen ${ }^{18} \mathrm{O}$. The ${ }^{18} \mathrm{O}$ diffuses

\footnotetext{
* Electrochemical Society Student Member.

a Present address: Siemens Westinghouse Power Corporation, Pittsburgh, Pennsylvania 15235 , USA.

ż-mail: keqin.huang@swpc.siemens.com
}

into the sample as a result of the existing ${ }^{18} \mathrm{O}$ chemical gradient $\left[\nabla \mu\left({ }^{18} \mathrm{O}\right)\right]$ with the ${ }^{18} \mathrm{O}$ ionic flux being internally balanced by the ionic flux of its counter isotope ${ }^{16} \mathrm{O}$. In this case, Fick's law governs the diffusional process. By fitting the measured ${ }^{18} \mathrm{O}$ profiles across the sample surface, the oxygen exchange coefficient $k_{\mathrm{s}}$ and the isotope oxygen diffusivity $D_{\mathrm{o}}^{*}$ can be obtained simultaneously. Many studies in this area have been carried out by Steele and Kilner. ${ }^{5-9}$ In the third method, the gradient of the chemical potential of oxygen $\left[\nabla \mu\left(\mathrm{O}_{2}\right)\right]$ across a mixed conducting oxide is the driving force for the oxygen diffusion. Different from the first two measurements, a true gradient of the chemical potential of oxygen is involved, and the oxide-ion flux is internally compensated by the electronic flux provided an ambipolar conduction prevails in the oxides. Therefore, a measure of oxide-ion flux could possibly offer a greater and better opportunity to determine oxide-ion conductivity since only oxide ions contribute to the permeation process in the presence of a pool of electrons. More studies ${ }^{10-12}$ have focused on this method to obtain the oxide-ion conductivity in electron-dominated mixed conductors. However, the prerequisite for this method is a lattice oxygen diffusion that rate-determines the overall permeation process. Any involvement of slow surface oxygen exchange could underevaluate the measured oxide-ion conductivity. This is especially true where thinner ceramic membranes are utilized in the permeation cell.

The technological significance of surface exchange kinetics has been increasingly realized in recent years, ${ }^{13-15}$ but a detailed description of the exchange process for oxide systems in terms of an exact reaction mechanism on an atomic scale, rate-determining steps, and adsorption site is still lacking. Steele ${ }^{13}$ and Bouwmeester et al. ${ }^{14}$ have both stressed the importance of surface exchange kinetics in determining the oxygen flux through oxide-ion conducting membranes. To obtain a high oxygen flux $J_{\mathrm{O}_{2}}$, it is desirable to have a thin membrane as indicated by the Wagner equation applicable where bulk oxygen diffusion dominates

$$
J_{\mathrm{O}_{2}}=-\frac{R T}{16 F^{2} L} \int_{p_{\mathrm{O}_{2}}^{\prime \prime}}^{p_{\mathrm{O}_{2}}^{\prime}} \frac{\sigma_{\mathrm{O}} \sigma_{\mathrm{e}}}{\sigma_{\mathrm{O}}+\sigma_{\mathrm{e}}} d \ln p_{\mathrm{O}_{2}}
$$

where $p_{\mathrm{O}_{2}}^{\prime}$ and $p_{\mathrm{O}_{2}}^{\prime \prime}$ are the partial pressures of oxygen of feeding gas and sweeping gas, respectively, $\sigma_{\mathrm{O}}$ and $\sigma_{\mathrm{e}}$ are the oxide-ion and electronic conductivities, respectively, and $\sigma_{\mathrm{O}} \sigma_{\mathrm{e}} /$ $\left(\sigma_{\mathrm{O}}+\sigma_{\mathrm{e}}\right)=\sigma_{\mathrm{ambi}}$ is the ambipolar conductivity. $L$ is the thickness of the membrane; $R, T$, and $F$ have their usual meanings. 


\begin{tabular}{lcc}
\hline $\begin{array}{l}\text { Table I. Final sintering temperatures for } \mathbf{L a}_{\mathbf{1}-\boldsymbol{x}} \mathbf{S r}_{\boldsymbol{x}} \mathbf{C o O}_{\mathbf{3}-\boldsymbol{\delta}} \text { and } \\
\mathbf{S r C o}_{\mathbf{0 . 8}} \mathbf{F e}_{\mathbf{0 . 2}} \mathbf{O}_{\mathbf{3 - \delta}} \cdot\end{array}$ & $\begin{array}{c}\text { Sintering } \\
\text { temperature }\left({ }^{\circ} \mathrm{C}\right)\end{array}$ & $\begin{array}{c}\text { Duration } \\
(\mathrm{h})\end{array}$ \\
Samples & & \\
\hline $\mathrm{La}_{1-x} \mathrm{Sr}_{x} \mathrm{CoO}_{3-\delta}$ & 1300 & 15 \\
$x=0.20$ & 1300 & 15 \\
$x=0.40$ & 1270 & 15 \\
$x=0.50$ & 1250 & 15 \\
$x=0.60$ & 1230 & 15 \\
$x=0.70$ & 1200 & 15 \\
$\mathrm{SrCo}_{0.8} \mathrm{Fe}_{0.2} \mathrm{O}_{3-\delta}$ & &
\end{tabular}

However, at or below the critical thickness $L_{\mathrm{c}}=D_{\mathrm{o}}^{*} / k_{\mathrm{s}}$ as defined by Bouwmeester et al., ${ }^{14}$ the surface exchange kinetics limits the oxygen flux. No further oxygen flux gain is achieved by making the membranes thinner. Note that the oxygen exchange kinetics at a gas-solid interface plays a fundamental role in the catalytic activity of the material. A correlation between oxygen exchange kinetics and catalytic activity has been established. ${ }^{16,17}$ A catalytic surface layer on a studied membrane could change the kinetics from surface exchange control to lattice diffusion control.

Of the known mixed conductors, the cobalt-containing oxides with perovskite structure have been most extensively studied because of their extremely high oxygen permeation rate at elevated temperatures; their potential applications are as ceramic membranes of chemical reactors and cathodes of a solid oxide fuel cell. In this paper, we report systematic measurements of the oxygen permeation fluxes through membranes of selected cobalt-containing perovskites by gas chromatography (GC). The results clearly indicate a mixed control over the total permeation rate by surface oxygen exchange and bulk oxygen diffusion. With a porous catalytic surface layer, the studied perovskite exhibits a changeover from mixed surface and bulk control to bulk control. The mechanisms for oxygen exchange kinetics on an atomic scale are discussed to interpret the results.

\section{Experimental}

Preparation of samples. - The studied samples have a formula $\mathrm{La}_{1-x} \mathrm{Sr}_{x} \mathrm{CoO}_{3-\delta}$ (LSCo) where $x=0.2,0.4,0.5,0.6$, and 0.7. The samples with $x>0.7$ were not investigated because they do not have a perovskite structure. The Pechini method was used to synthesize the $\mathrm{La}_{1-x} \mathrm{Sr}_{x} \mathrm{CoO}_{3-\delta}$ compounds. Details about this method are described in Ref. 18 and 19. The decomposed ceramic powders were ballmilled to break up the soft agglomerates and pressed into 1 in. diam pellets under $200 \mathrm{MPa}$ pressure. The final sintering temperatures and duration for each composition are listed in Table I. For comparison, $\mathrm{SrCo}_{0.8} \mathrm{Fe}_{0.2} \mathrm{O}_{3-\delta}(\mathrm{SCF})$ was also made in this study by solid-state reaction. The powders were ground three times after each $1000^{\circ} \mathrm{C}$ calcination and finally sintered at $1200^{\circ} \mathrm{C}$ for $15 \mathrm{~h}$.

Whether lattice oxygen diffusion or surface oxygen exchange limits the overall permeation rate through a mixed ionic and electronic conductor (MIEC) is primarily determined by the relative magnitude of the rates of lattice diffusion and surface exchange. To enhance the rate of reaction at the surfaces of LSCo samples so as to make lattice oxygen diffusion the rate-determining step, a thin layer of SCF, which has been reported previously to have the highest oxygen permeation flux among the MIECs discovered, ${ }^{20,21}$ was applied directly by pasting an SCF ink either on one surface of LSCo or on both. The SCF ink was made by thoroughly mixing fine SCF powders with organic binder (V-6 manufactured by Heraeus Inc.), terpineol, and oleic acid in a certain ratio. The coated LSCo was then fired at $1200^{\circ} \mathrm{C}$ for $30 \mathrm{~min}$ to increase the bonding between the coating and substrate. From our previous experience, the microstructures of the coating resulting from the above ink are mesoporous.

Powder X-ray diffraction (XRD) was performed on a PW 1740 diffractometer from 10 to $80^{\circ}$ with $\mathrm{Cu} \mathrm{K} \alpha$ radiation and a Ni filter.

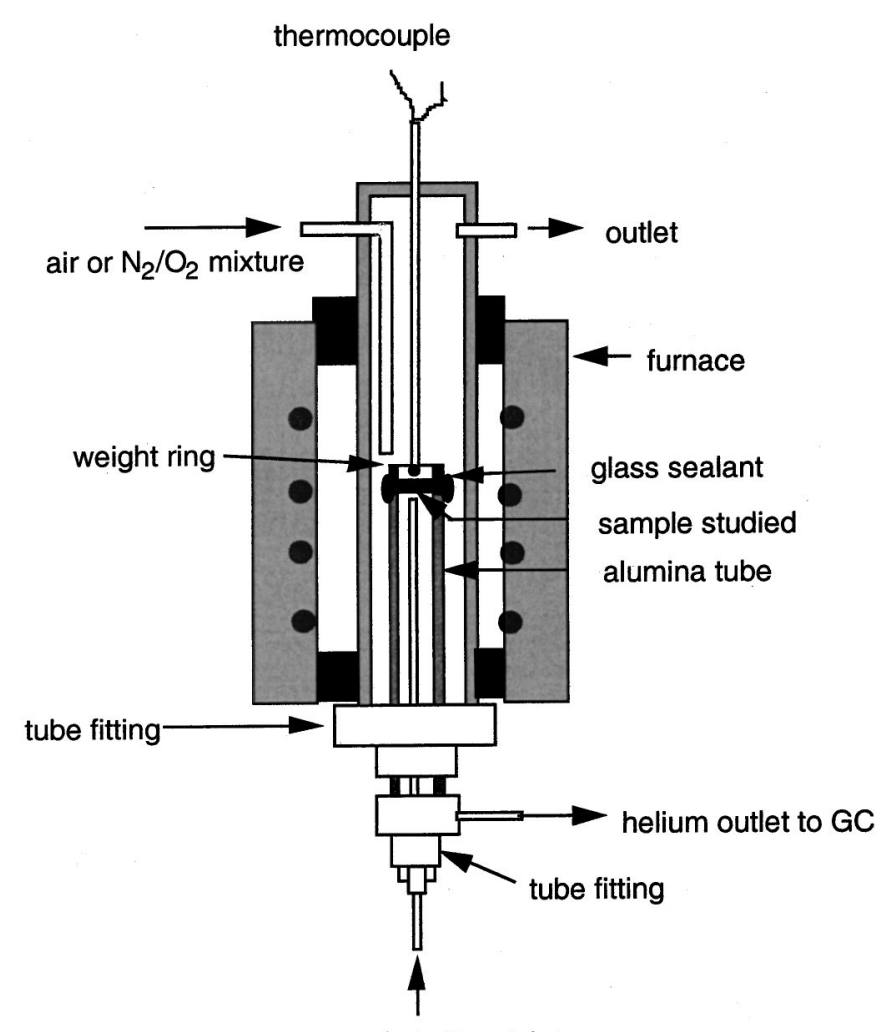

Figure 1. Experimental setup for oxygen permeation measurements.

Synthetic silicon powder as an internal standard was used for determining the lattice parameters. From the XRD patterns, the structures and the related lattice parameters were determined with Rietveld refinement.

Oxygen permeation measurement.-The aforementioned sintered pellets, which usually shrank to $\sim 0.7$ in. diam, were first ground on both sides with a diamond wheel to a desired thickness. The grinding also ensured removal of possibly contaminated surface layers. The fresh pellets thus obtained were then mounted on the top of a supporting alumina tube with a glass ring that was covered with a glass-powder slurry to ensure further sealing. An alumina ring (the same size as the supporting tube) on the top of the sample was also used as a weight to keep the seal leak-tight while maintaining the same permeation area on both sides of the sample. To eliminate the edge effect (extra oxygen permeation through uncounted area), the outer glass-powder slurry covers the overall edges of the sample. The whole setup of the permeation cell is illustrated in Fig. 1. The assembly was then loaded into the constant-temperature zone of a vertical furnace and slowly heated to $900-950^{\circ} \mathrm{C}$ to allow the glass to soften and seal the assembly. The measurement proceeded in a cooling sequence.

GC with a $5 \AA$ molecular-sieve column and a thermal conductivity detector was used to measure the oxygen contents in the sweeping helium (purity $>99.999 \%$ ) because simultaneously measuring the nitrogen content can monitor the leak-tightness of a permeation cell. The oxygen concentration in the sweeping helium was measured at a given flow rate, and ambient air or an $\mathrm{N}_{2}-\mathrm{O}_{2}$ mixture at a flow rate of $45 \mathrm{~mL} / \mathrm{min}$ was used as the feeding gas at the other side of the permeation cell. A special six-port Valco valve was employed to inject the sample gas into an SRI 8610C GC when needed. PeakSimple software was used to collect and analyze the data by integrating the individual peak areas corresponding to either oxygen or nitrogen. The column was calibrated usually once a month with $\mathrm{He}-0.1 \% \quad \mathrm{O}_{2}$ and $\mathrm{He}-1 \% \quad \mathrm{O}_{2}$ mixtures as the standard 


\begin{tabular}{|c|c|c|c|}
\hline Samples & Symmetry & $a(r)(\AA)$ & $\alpha(r)^{(\mathrm{o})}$ \\
\hline \multicolumn{4}{|l|}{$\mathrm{La}_{1-x} \mathrm{Sr}_{x} \mathrm{CoO}_{3-\delta}$} \\
\hline$x=0.2$ & Rhombohedral & $3.836(4)$ & 90.48 \\
\hline$x=0.4$ & Rhombohedral & $3.835(4)$ & 90.23 \\
\hline$x=0.5$ & Rhombohedral & $3.833(4)$ & 90.14 \\
\hline$x=0.6$ & Cubic & $3.834(1)$ & 90.00 \\
\hline$x=0.7$ & Cubic & $3.837(1)$ & 90.00 \\
\hline $\mathrm{SrCo}_{0.8} \mathrm{Fe}_{0.2} \mathrm{O}_{3-\delta}$ & Cubic & $3.853(0)$ & 90.00 \\
\hline
\end{tabular}

gases depending on how heavily the GC was used. For all measurements, the flow rate of the carrier helium gas (purity $>99.999 \%$ ) for carrying effluent (the sweeping gas in a $1 \mathrm{~mL}$ sample loop on the valve in this case) into the GC for analysis was $20 \mathrm{~mL} / \mathrm{min}$. Any detectable nitrogen was regarded as leakage from air, and the corresponding oxygen content was subtracted from the measured value. If the nitrogen content was above $0.1 \%$, the measurement was abandoned. If the continuously stirred tank reactor condition is satisfied in our permeation cell and the sweeping helium behaves ideally, the oxygen permeation flux $J_{\mathrm{O}_{2}}$ can be calculated from the flow rate of the sweeping gas, the volume fraction of oxygen analyzed by GC, and the effective permeation area.

The variations of chemical potential gradient of oxygen across the MIEC were achieved by either changing the flow rate of the sweeping helium gas while keeping the feeding gas as ambient air $\left(p_{\mathrm{O}_{2}}^{\prime}=0.21 \mathrm{~atm}\right)$, or by altering the ratio of $\mathrm{O}_{2}$ in an $\mathrm{N}_{2}-\mathrm{O}_{2}$ mixture as the feeding gas while keeping the flow rate of sweeping helium gas constant, normally $20 \mathrm{~mL} / \mathrm{min}$. In the former case, the flow rate of the sweeping helium gas, usually ranging from 5 to $150 \mathrm{~mL} / \mathrm{min}$, was regulated by a mass flow controller (MFC), (MKS model 1179A with four-channel readout unit model 247). A smaller flow rate usually requires longer equilibration times. Therefore, at each temperature, the measurement was started from the smallest flow rate and was held overnight to ensure that real equilibrium was achieved. In the latter case, the oxygen content in the feeding gas was changed by varying the flow rates of oxygen and nitrogen, which are also regulated by the MFC. Similar to the former case, the permeation measurement was started from the lowest partial pressure of oxygen, and the cell was held overnight at high temperatures before continuing to the next $p_{\mathrm{O}_{2}}$. Each measurement takes approximately $8 \mathrm{~h}$ at each temperature.

\section{Results and Discussion}

Structural changes as a function of $\mathrm{Sr}$ content.-The lattice parameters of both $\mathrm{La}_{1-x} \mathrm{Sr}_{x} \mathrm{CoO}_{3-\delta}$ and $\mathrm{SrCo}_{0.8} \mathrm{Fe}_{0.2} \mathrm{O}_{3-\delta}$ samples are listed in Table II. Consistent results with those reported in the literature ${ }^{22}$ were obtained. For $x=0.2,0.4$, and 0.5 , the structure is rhombohedral, which distorts from the cubic by an angle $\left|\alpha(r)-90^{\circ}\right|$. It is apparent from Table II that the extent of distortion decreases with increasing $x$ to $x=0.5$, above which the structures change to primitive cubic without distortion. The lattice parameter $a(r)$ shows a slight decrease with increasing $x$, but $\alpha(r)$ exhibits a pronounced monotonous decrease. From the following results, it appears that $\alpha(r)$, and therefore the Co-O-Co bond angle, has a more profound effect on the oxide-ion conductivity than $a(r)$ as is discussed in detail in the section on Mechanisms for both surface oxygen exchange and bulk oxygen diffusion control. Unlike previous reports, ${ }^{20,21}$ a small amount of unknown impurity is consistently found in the primitive cubic matrix of air-annealed $\mathrm{SrCo}_{0.8} \mathrm{Fe}_{0.2} \mathrm{O}_{3-\delta}$ even after several intermediate grindings. How- ever, it gives a pure primitive cubic phase after annealing in oxygen. The lattice parameters of $\mathrm{SrCo}_{0.8} \mathrm{Fe}_{0.2} \mathrm{O}_{3-\delta}$ shown in Table II were obtained from an oxygen-annealed sample.

Oxygen permeation flux $J_{O_{2}}$ without catalytic surface layer.-In the following paragraphs, $p_{\mathrm{O}_{2}}^{\prime}$ and $p_{\mathrm{O}_{2}}^{\prime \prime}$ denote the partial pressures of oxygen at the feeding and the permeate side, $p_{\mathrm{O}_{2}}^{\prime}>p_{\mathrm{O}_{2}}^{\prime \prime}$, respectively. Unless especially mentioned, we choose the composition $\mathrm{La}_{0.5} \mathrm{Sr}_{0.5} \mathrm{CoO}_{3-\delta}$ as a representative example of the $\mathrm{La}_{1-x} \mathrm{Sr}_{x} \mathrm{CoO}_{3-\delta}$ system. Most of the experimental data can be found in Table III.

Previous studies ${ }^{23,24}$ have shown a power law with the index $n<0$ between oxygen nonstoichiometry $\delta$ and the oxygen partial pressure $p_{\mathrm{O}_{2}}$ in the $\mathrm{La}_{1-x} \mathrm{Sr}_{x} \mathrm{CoO}_{3-\delta}$ system at elevated temperatures. One can then expect, from the Wagner equation with $\sigma_{\text {ambi }}$ $\approx \sigma_{\text {ambi }}^{\mathrm{O}} p_{\mathrm{O}_{2}}^{\mathrm{n}}(n<0)$, a straight-line plot of $J_{\mathrm{O}_{2}} v s . p_{\mathrm{O}_{2}}^{\prime \mathrm{n}}-p_{\mathrm{O}_{2}}^{\prime \prime \mathrm{n}}$ with $n<0$, provided the overall permeation is rate determined by bulk oxygen diffusion. The ambipolar conductivity $\sigma_{\text {ambi }}$ $\sim \exp \left(-E_{\mathrm{a}} / k T\right)$ can be calculated from the slope of the line by using Wagner's equation.

$J_{\mathrm{O}_{2}}$ under $p_{\mathrm{O}_{2}}^{\prime}=0.21 \mathrm{~atm}$ and varied $p_{\mathrm{O}_{2}}^{\prime \prime}$.- The oxygen partial pressure $p_{\mathrm{O}_{2}}^{\prime \prime}$ in the sweeping helium has a power law relationship with its flow rate $F$ for $\mathrm{La}_{0.5} \mathrm{Sr}_{0.5} \mathrm{CoO}_{3-\delta}$ (see Fig. 2). Since the oxygen flux $J_{\mathrm{O}_{2}}$ is proportional to the product of $p_{\mathrm{O}_{2}}^{\prime \prime}$ and $F$, the observed power law relationship implies that $J_{\mathrm{O}_{2}}$ is proportional to $p_{\mathrm{O}_{2}}^{\prime \prime m}(m=1-1 / s, m<0)$ if no cell leakage is considered. It appears to conflict with the results shown in Fig. 5, where a positive power index $n$ in $J_{\mathrm{O}_{2}}$ vs. $p_{\mathrm{O}_{2}}^{\prime \mathrm{n}}-p_{\mathrm{O}_{2}}^{\prime \prime n}$ is observed. We believe this deviation results from two factors. First, the existence of a certain amount of cell leakage requires using different $p_{\mathrm{O}_{2}}^{\prime \prime}$ for plotting Fig. 2 (not corrected for air leak) and for calculating $J_{\mathrm{O}_{2}}$ (corrected for air leak). Second, the power index $n$ in $J_{\mathrm{O}_{2}} v s . p_{\mathrm{O}_{2}}^{\prime n}-p_{\mathrm{O}_{2}}^{\prime \prime n}$ was obtained by a nonlinear least-squares fitting with the justification of boundary condition of $J_{\mathrm{O}_{2}}=0$ at $p_{\mathrm{O}_{2}}^{\prime}=p_{\mathrm{O}_{2}}^{\prime \prime}$, while no boundary condition is required for the relationship of $p_{\mathrm{O}_{2}}^{\prime \prime}$ and $F$ shown in Fig. 2.

The temperature dependence of the measured overall oxygen permeation flux at different driving forces $\log \left(p_{\mathrm{O}_{2}}^{\prime} / p_{\mathrm{O}_{2}}^{\prime \prime}\right)$ for the composition $\mathrm{La}_{0.5} \mathrm{Sr}_{0.5} \mathrm{CoO}_{3-\delta}$ is illustrated in Fig. 3. By the Wagner equation, this dependence can only be meaningfully established at a given sample thickness and driving force $\log \left(p_{\mathrm{O}_{2}}^{\prime} / p_{\mathrm{O}_{2}}^{\prime \prime}\right)$. As clearly shown in the figure, $\log \left(J_{\mathrm{O}_{2}}\right)$ vs. $1 / T$ at a given driving force yields a straight line; the activation energy $E_{\mathrm{a}}$ for the permeation process can be calculated from the slope. These results are very close to those obtained from the slope of $J_{\mathrm{O}_{2}} v s . p_{\mathrm{O}_{2}}^{\prime n}-p_{\mathrm{O}_{2}}^{\prime \prime n}$ shown in Table III, but they depend strongly on the Co-O-Co bond angle and/or Sr-doping level. Note that $E_{\mathrm{a}}$ might not represent a single process; it could include both surface exchange and bulk diffusion.

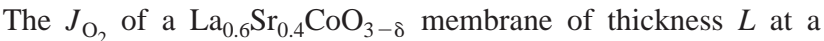
given temperature and driving force $\log \left(p_{\mathrm{O}_{2}}^{\prime} / p_{\mathrm{O}_{2}}^{\prime \prime}\right)$ is plotted against $1 / L$ in Fig. 4. Although $J_{\mathrm{O}_{2}}$ increases roughly inversely with $L$ for larger $L$, it is very hard to distinguish the bulk and surface control by this plot because there is no sample thicker than $1.7 \mathrm{~mm}$ in this portion of the study, which was intended to reach a critical value $L_{\mathrm{c}}$. Other compositions gave similar results; even at a thickness of $2.5 \mathrm{~mm}$, a slow surface exchange appears to be controlling for the cobalt-containing perovskites. The concept of the critical length ${ }^{14} L_{\mathrm{c}}$ has been proposed by assuming a linearized surface exchange and bulk diffusion at a small $p_{\mathrm{O}_{2}}$ gradient. It may not be applicable in our case. 
Table III. Nonlinear least-squares fitting data on $J_{\mathrm{O}_{2}}=\theta\left(p_{\mathrm{O}_{2}}^{\prime \mathrm{n}}-p_{\mathrm{O}_{2}}^{\prime \prime \mathrm{n}}\right)$, where $p_{\mathrm{O}_{2}}^{\prime}=0.21 \mathrm{~atm}, 0.21 \mathrm{~atm}>p_{\mathrm{O}_{2}}^{\prime \prime}>5 \times 10^{-4} \mathrm{~atm}$. Samples have no catalytic layer SCF on the surface.

\begin{tabular}{|c|c|c|c|c|c|c|}
\hline Sample & $\begin{array}{l}\text { Thickness } \\
\text { (mm) }\end{array}$ & $\begin{array}{c}T \\
\left({ }^{\circ} \mathrm{C}\right)\end{array}$ & Order $(n)$ & $\begin{array}{l}n \text { by TGA } \\
\left(800^{\circ} \mathrm{C}\right)^{23}\end{array}$ & $\begin{array}{c}\theta \\
\left(\mathrm{mol} \mathrm{cm}{ }^{-2} \mathrm{~s}^{-1} \mathrm{~atm}^{-\mathrm{n}}\right)\end{array}$ & $\begin{array}{l}\text { Activation } \\
\text { energies } \\
(\mathrm{eV})\end{array}$ \\
\hline \multicolumn{7}{|l|}{$\mathrm{La}_{1-x} \mathrm{Sr}_{x} \mathrm{CoO}_{3-\delta}$} \\
\hline \multirow{3}{*}{$x=0.2$} & & 910 & $-0.20 \pm 0.08$ & & $1.66 \times 10^{-8}$ & \\
\hline & & 890 & $-0.30 \pm 0.05$ & & $1.22 \times 10^{-8}$ & \\
\hline & & 870 & $-0.35 \pm 0.09$ & & $8.37 \times 10^{-9}$ & \\
\hline \multirow{3}{*}{$x=0.4$} & & 910 & $0.21 \pm 0.03$ & & $2.76 \pm 0.13 \times 10^{-7}$ & \\
\hline & & 890 & $0.16 \pm 0.03$ & & $2.45 \pm 0.28 \times 10^{-7}$ & \\
\hline & & 850 & $0.10 \pm 0.04$ & & $1.85 \pm 0.45 \times 10^{-7}$ & \\
\hline \multirow{4}{*}{$x=0.5$} & 1.34 & 930 & $0.21 \pm 0.03$ & -0.07 & $3.48 \pm 0.17 \times 10^{-7}$ & $1.56 \pm 0.05$ \\
\hline & & 910 & $0.25 \pm 0.03$ & & $3.02 \pm 0.07 \times 10^{-7}$ & \\
\hline & & 890 & $0.26 \pm 0.03$ & & $2.23 \pm 0.05 \times 10^{-7}$ & \\
\hline & & 870 & $0.27 \pm 0.03$ & & $1.61 \pm 0.03 \times 10^{-7}$ & \\
\hline \multirow{5}{*}{$x=0.6$} & & 910 & $0.34 \pm 0.05$ & & $5.58 \pm 0.08 \times 10^{-7}$ & \\
\hline & & 890 & $0.37 \pm 0.02$ & & $4.94 \pm 0.02 \times 10^{-7}$ & \\
\hline & & 870 & $0.29 \pm 0.08$ & & $4.52 \pm 0.26 \times 10^{-7}$ & \\
\hline & & 850 & $0.25 \pm 0.09$ & & $3.98 \pm 0.46 \times 10^{-7}$ & \\
\hline & & 830 & $0.28 \pm 0.08$ & & $3.28 \pm 0.23 \times 10^{-7}$ & \\
\hline \multirow{6}{*}{$x=0.7$} & 2.50 & 910 & $0.41 \pm 0.07$ & -0.05 & $7.95 \pm 0.26 \times 10^{-7}$ & $0.88 \pm 0.07$ \\
\hline & & 890 & $0.20 \pm 0.05$ & & $7.67 \pm 0.78 \times 10^{-7}$ & \\
\hline & & 870 & $0.24 \pm 0.09$ & & $6.68 \pm 0.75 \times 10^{-7}$ & \\
\hline & & 850 & $0.27 \pm 0.10$ & & $5.57 \pm 0.46 \times 10^{-7}$ & \\
\hline & & 830 & $0.32 \pm 0.10$ & & $4.55 \pm 0.14 \times 10^{-7}$ & \\
\hline & & 810 & $0.41 \pm 0.05$ & & $3.71 \pm 0.08 \times 10^{-7}$ & \\
\hline \multirow{2}{*}{$\mathrm{SrCo}_{0.8} \mathrm{Fe}_{0.2} \mathrm{O}_{3-\delta}$} & 1.48 & 930 & $0.82 \pm 0.15$ & --- & $3.40 \pm 0.60 \times 10^{-6}$ & $0.52 \pm 0.07$ \\
\hline & 1.70 & 910 & $0.83 \pm 0.20$ & & $3.24 \pm 0.73 \times 10^{-6}$ & $0.22-0.01$ \\
\hline
\end{tabular}

${ }^{a}$ Other thicknesses are not shown in this table.

As shown in Table III, an $n<0$ close to the value obtained by thermogravimetric analysis (TGA) is only observed for the $x$ $=0.2$ sample. The agreement indicates a bulk diffusion dominating the permeation. The calculated ambipolar conductivity for this composition is $\sigma_{\mathrm{O}}=(3.49 \pm 0.59) \times 10^{8} \exp (-1.78 \pm 0.14(\mathrm{eV}) /$ $k T$ ) from which $\sigma_{O} \approx 0.01 \mathrm{~S} / \mathrm{cm}$ at $930^{\circ} \mathrm{C}$ is obtained. The low value of $\sigma_{\mathrm{O}}$ and high value of $E_{\mathrm{a}}$ are due to the presence of a dynamic phase segregation in the $x=0.2$ composition. ${ }^{25}$ However, an $n>0$ is found for the other compositions. Figure 5 presents such a plot for $x=0.5$ with fitted lines passing through the origin $(0,0)$. The optimized $n$ by nonlinear least-squares fitting is obtained as $0.5>n>0$. If the bulk diffusion is assumed to prevail, then $n>0$ implies an oxygen interstitial mechanism for the transport of charge carriers. This is impossible for the perovskite structure because there is no possible interstitial position for oxygen in the structure.

Therefore, it is certain that a mixed surface exchange and bulk diffusion control the permeation rate or a sole surface exchange control is responsible for the $n>0$ as is discussed in the section on Mechanisms. Also, thinner samples yield $n$ much closer to 0.5 , which also supports such an assumption. By a similar treatment, 1 $>n>0.5$ has been calculated for $\mathrm{O}_{2}$ adsorption at $\mathrm{Fe}^{3+}$ and is found in $\mathrm{SrCo}_{0.8} \mathrm{Fe}_{0.2} \mathrm{O}_{3-\delta}$, as shown in Fig. 6. This result disagrees with that in, ${ }^{26}$ where $n=0.5$ was claimed. Thus, different mechanisms have been involved for these two types of compounds.

Note that no linear dependence of $J_{\mathrm{O}_{2}}$ on $\log \left(p_{\mathrm{O}_{2}}^{\prime} / p_{\mathrm{O}_{2}}^{\prime \prime}\right)$ that passes through $(0,0)$ can be found in this study. Determination of oxide-ion conductivity from the slope of the $J_{\mathrm{O}_{2}} v s . \log \left(p_{\mathrm{O}_{2}}^{\prime} / p_{\mathrm{O}_{2}}^{\prime \prime}\right)$ line without justifying at $J_{\mathrm{O}_{2}}=0$ at $p_{\mathrm{O}_{2}}^{\prime}=p_{\mathrm{O}_{2}}^{\prime \prime}$ would contain errors.

$J_{\mathrm{O}_{2}}$ under varied $p_{\mathrm{O}_{2}}^{\prime}$ and fixed sweeping-gas flow rate.-With a fixed sweeping-gas flow rate, the gradient of the partial pressure of oxygen is determined by variations of both $p_{\mathrm{O}_{2}}^{\prime}$ and $p_{\mathrm{O}_{2}}^{\prime \prime}$, whereas only $p_{\mathrm{O}_{2}}^{\prime \prime}$ changes as a result of variation of the sweeping-gas flow rate in the experiment with a fixed $p_{\mathrm{O}_{2}}^{\prime}=0.21 \mathrm{~atm}$. Comparison of the results from the two types of experiments should reveal the effect of partial pressures of oxygen in the feeding gas and of the flowing patterns of the sweeping gas on the surface reaction kinetics.

The variations of $p_{\mathrm{O}_{2}}^{\prime \prime}$ as a function of $p_{\mathrm{O}_{2}}^{\prime}$ are shown in Fig. 7 for a fixed sweeping-gas flow rate of $20 \mathrm{~mL} / \mathrm{min}$. All curves taken at 


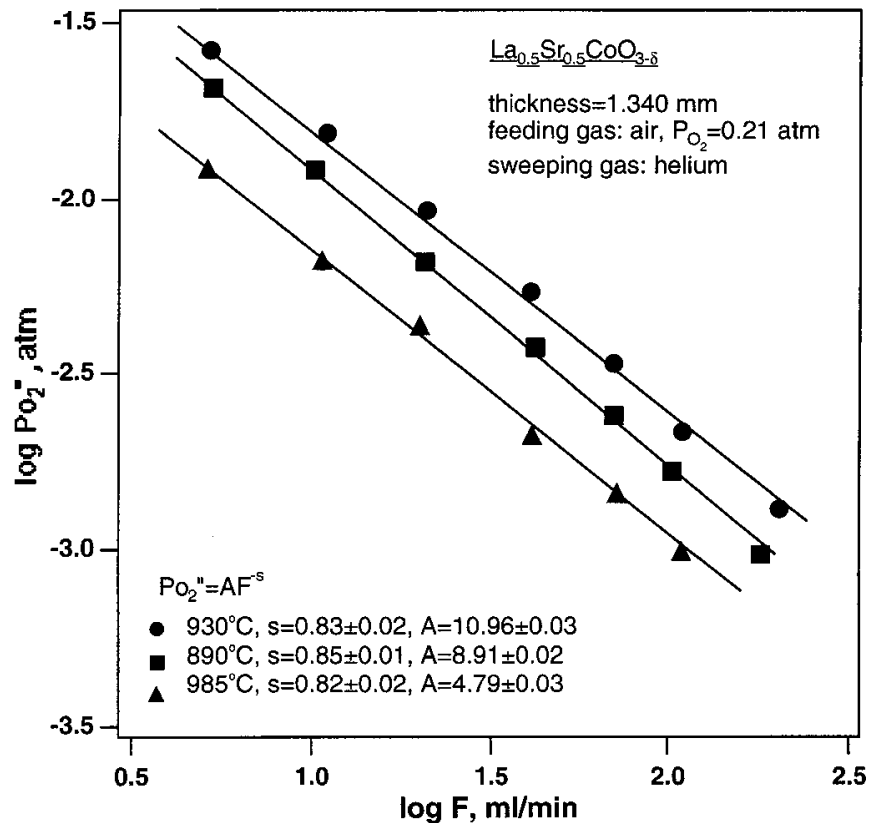

Figure 2. Dependence of $p_{\mathrm{O}_{2}}^{\prime \prime}$ on flow rate of sweeping helium at different temperatures for $\mathrm{La}_{0.5} \mathrm{Sr}_{0.5} \mathrm{CoO}_{3-\delta}$.

various temperatures show a similar trend, i.e., the rate of increase of $p_{\mathrm{O}_{2}}^{\prime \prime}$ with $p_{\mathrm{O}_{2}}^{\prime}$ decreases with increasing $p_{\mathrm{O}_{2}}^{\prime}$ and decreasing temperature $T$. The measured $p_{\mathrm{O}_{2}}^{\prime \prime}$ could be a combined result of oxygen diffusion in the bulk and surface oxygen exchange kinetics at both surfaces. Plots of oxygen flux $J_{\mathrm{O}_{2}} v s$. the gradient of the partial pressure of oxygen $\log \left(p_{\mathrm{O}_{2}}^{\prime} / p_{\mathrm{O}_{2}}^{\prime \prime}\right)$ at different temperatures reveal a clearer picture (see Fig. 8). An increase in the gradient increases the

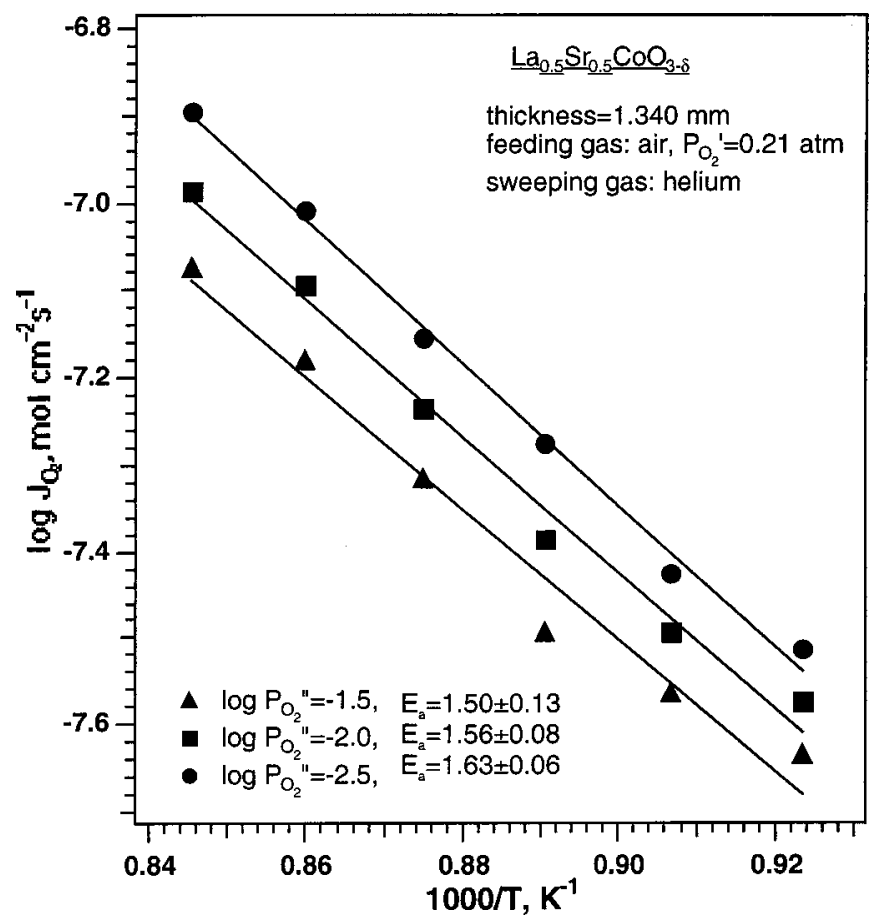

Figure 3. Arrhenius plot of $J_{\mathrm{O}_{2}}$ under a given gradient of chemical potential of oxygen for $\mathrm{La}_{0.5} \mathrm{Sr}_{0.5} \mathrm{CoO}_{3-\delta}$.

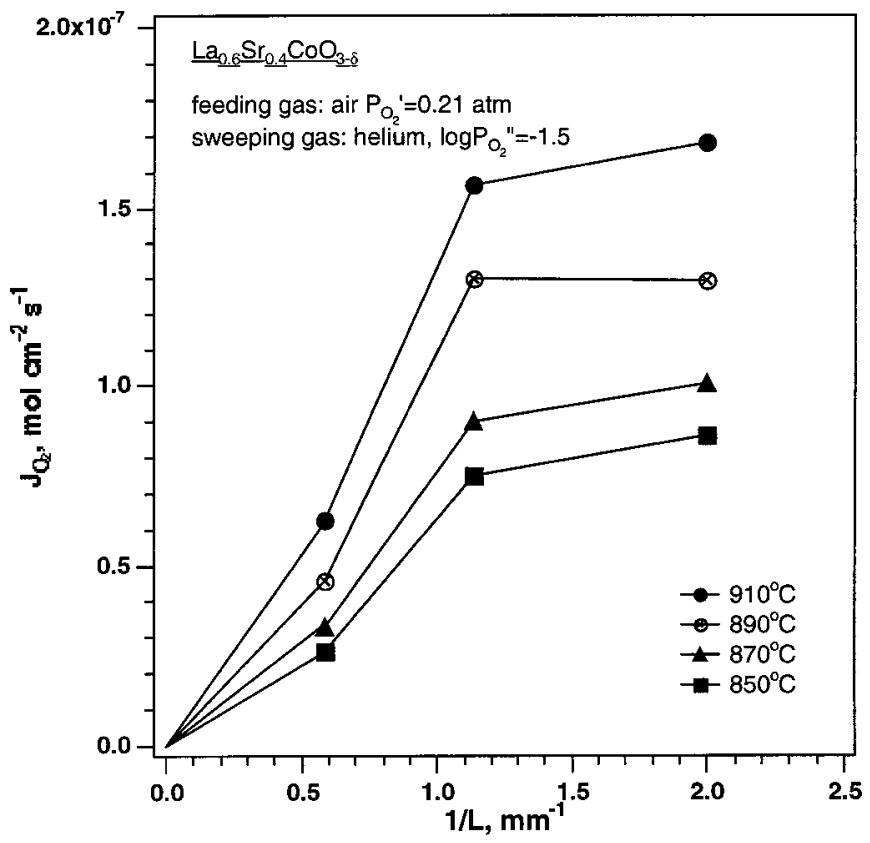

Figure 4. Thickness dependence of $J_{\mathrm{O}_{2}}$ at different temperatures and a given gradient of chemical potential of oxygen for $\mathrm{La}_{0.6} \mathrm{Sr}_{0.4} \mathrm{CoO}_{3-\delta}$.

oxygen flux more effectively at higher temperatures than at lower temperatures. This finding, in turn, implies that the surface reaction kinetics has an activation energy higher than that of bulk oxygen diffusion. In fact, at $800^{\circ} \mathrm{C}, J_{\mathrm{O}_{2}}$ tends to approach a saturation value with increasing $\log \left(p_{\mathrm{O}_{2}}^{\prime} / p_{\mathrm{O}_{2}}^{\prime \prime}\right)$. As stated above, no linear relationship that passes through $(0,0)$ can be found in Fig. 8 over the measured $T$ and $\log \left(p_{\mathrm{O}_{2}}^{\prime} / p_{\mathrm{O}_{2}}^{\prime \prime}\right)$ ranges. Nevertheless, plots of $J_{\mathrm{O}_{2}}$ vs. $p_{\mathrm{O}_{2}}^{\prime \mathrm{n}}$ $-p_{\mathrm{O}_{2}}^{\prime \prime \text { n }}$ (Fig. 9) have been well fitted by straight lines with a 0.5

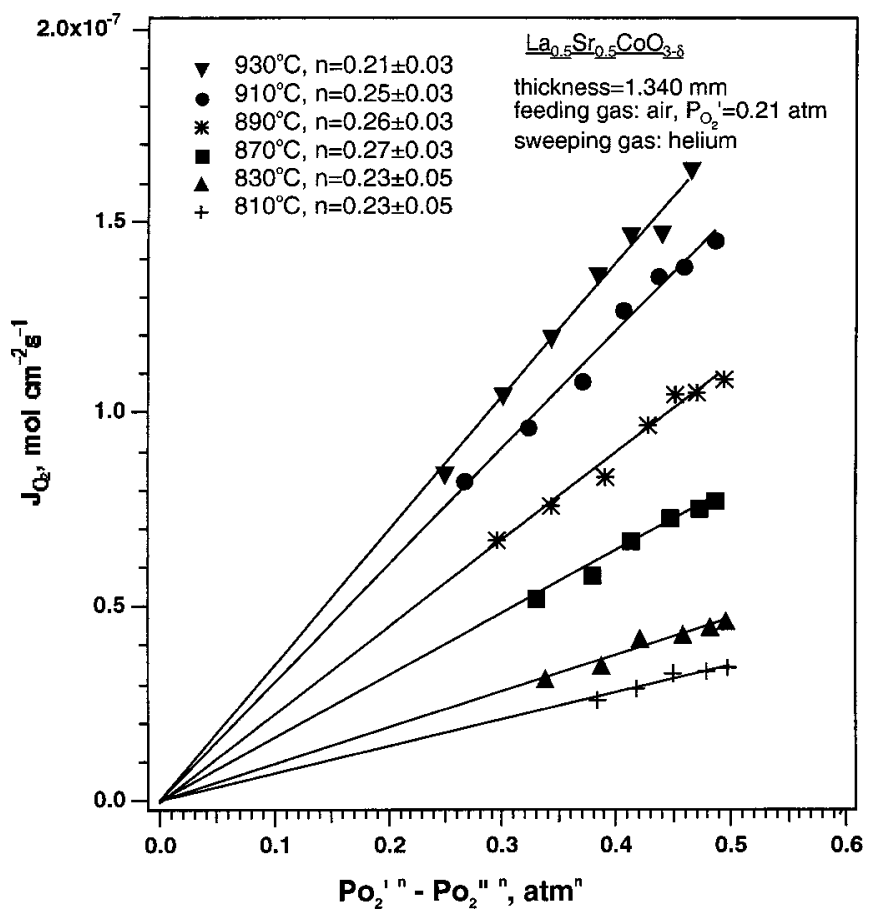

Figure 5. Power law dependence of $J_{\mathrm{O}_{2}}$ on the partial pressure of oxygen for $\mathrm{La}_{0.5} \mathrm{Sr}_{0.5} \mathrm{CoO}_{3-\delta}$. 


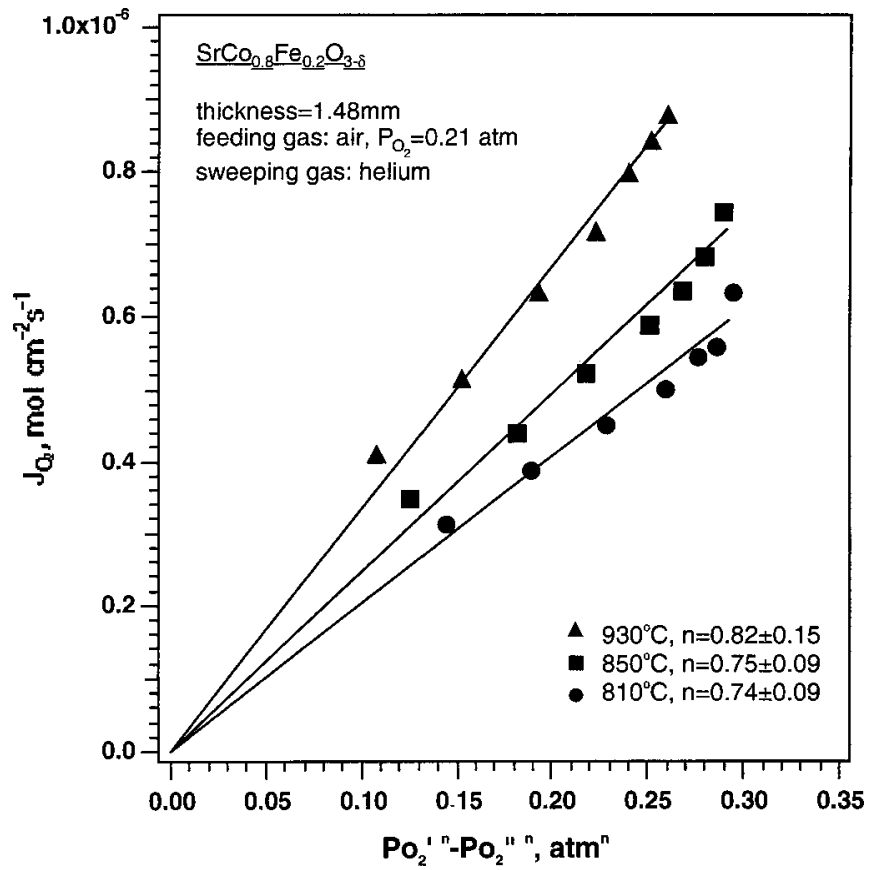

Figure 6. Power law dependence of $J_{\mathrm{O}_{2}}$ on the partial pressure of oxygen for $\mathrm{SrCo}_{0.8} \mathrm{Fe}_{0.2} \mathrm{O}_{3-\delta}$.

$>n>0$ over $800-900^{\circ} \mathrm{C}$. According to the model developed in this study, $0.5>n>0$ indicates a mixed surface exchange and bulk diffusion of oxygen involved in the overall permeation process. However, in Fig. 9, $n$ is a bit larger at high temperatures than that shown in Fig. 5, although the sample of Fig. 9 is thicker than that of Fig. 5. This result appears to contradict the aforementioned statement that the value of $n$ approaches 0.5 when the sample thickness decreases. Bearing in mind that the partial pressure of oxygen $p_{\mathrm{O}_{2}}^{\prime}$ in the feeding gas in Fig. 9 varies approximately from $10^{-3}$ to $1 \mathrm{~atm}$, whereas $p_{\mathrm{O}_{2}}^{\prime}$ is kept a constant 0.21 atm in Fig. 5, the discrepancy suggests that there is an effect of the partial pressure of oxygen on

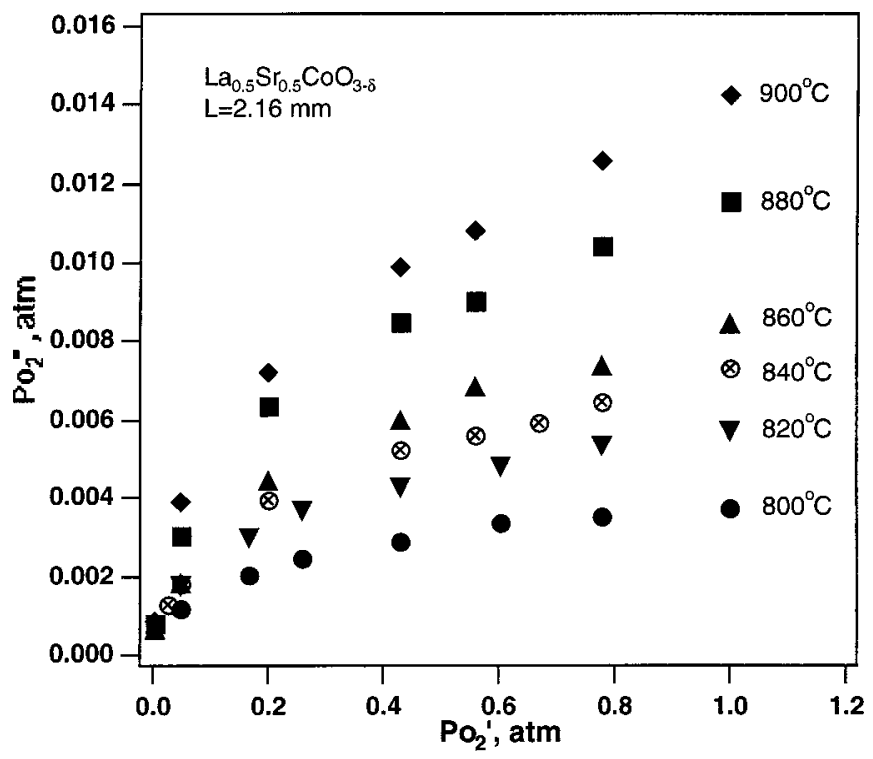

Figure 7. $p_{\mathrm{O}_{2}}^{\prime \prime}$ as a function of $p_{\mathrm{O}_{2}}^{\prime}$ at various temperatures. The $p_{\mathrm{O}_{2}}^{\prime}$ was varied by changing the $\mathrm{O}_{2} / \mathrm{N}_{2}$ ratio in the feeding gas.

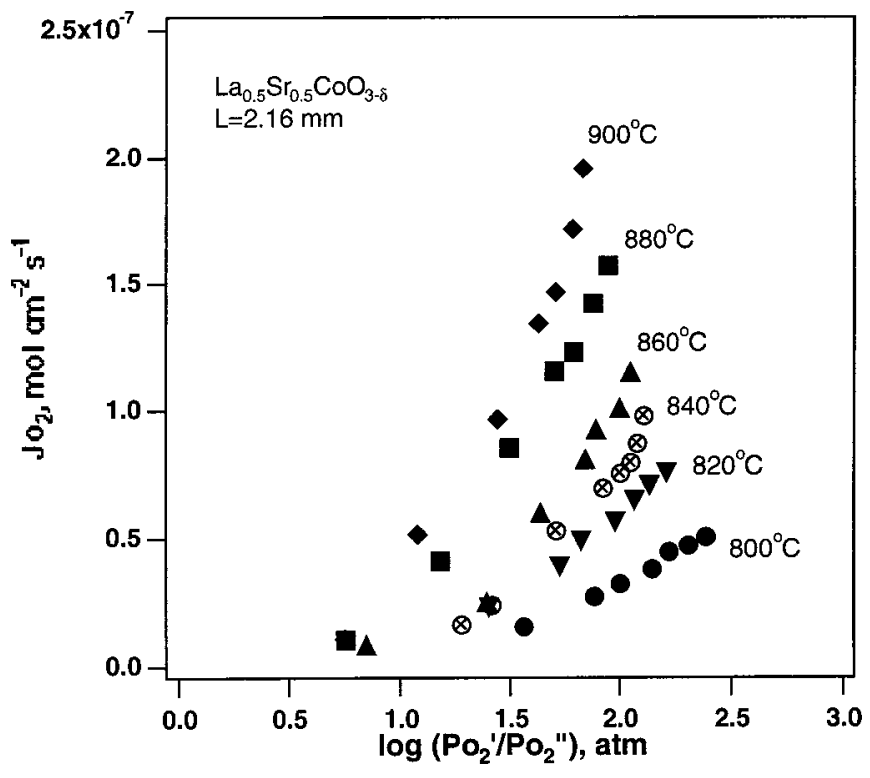

Figure 8. Dependence of $J_{\mathrm{O}_{2}}$ on the gradient of partial pressure of oxygen for $\mathrm{La}_{0.5} \mathrm{Sr}_{0.5} \mathrm{CoO}_{3-\delta}$. The gradient of partial pressure of oxygen was varied as a result of changes of both $p_{\mathrm{O}_{2}}^{\prime}$ and $p_{\mathrm{O}_{2}}^{\prime \prime}$.

the surface kinetics at the feeding-gas side. This assumption is supported in the following section. A logarithmic plot of the slope acquired from Fig. 9 vs. 1/T yields an apparent activation energy $E_{\mathrm{a}}=1.41 \mathrm{eV}$, which is comparable to $1.56 \mathrm{eV}$ in Table III for the same but thinner sample.

Oxygen permeation flux $\mathrm{J}_{\mathrm{O}_{2}}$ with a catalytic surface layer.- $\mathrm{J}_{\mathrm{O}_{2}}$ under $p_{\mathrm{O}_{2}}^{\prime}=0.21 \mathrm{~atm}$ and varied $p_{\mathrm{O}_{2}}^{\prime \prime}$.- It is expected that a layer of catalytically active SCF coating will promote the surface oxygen

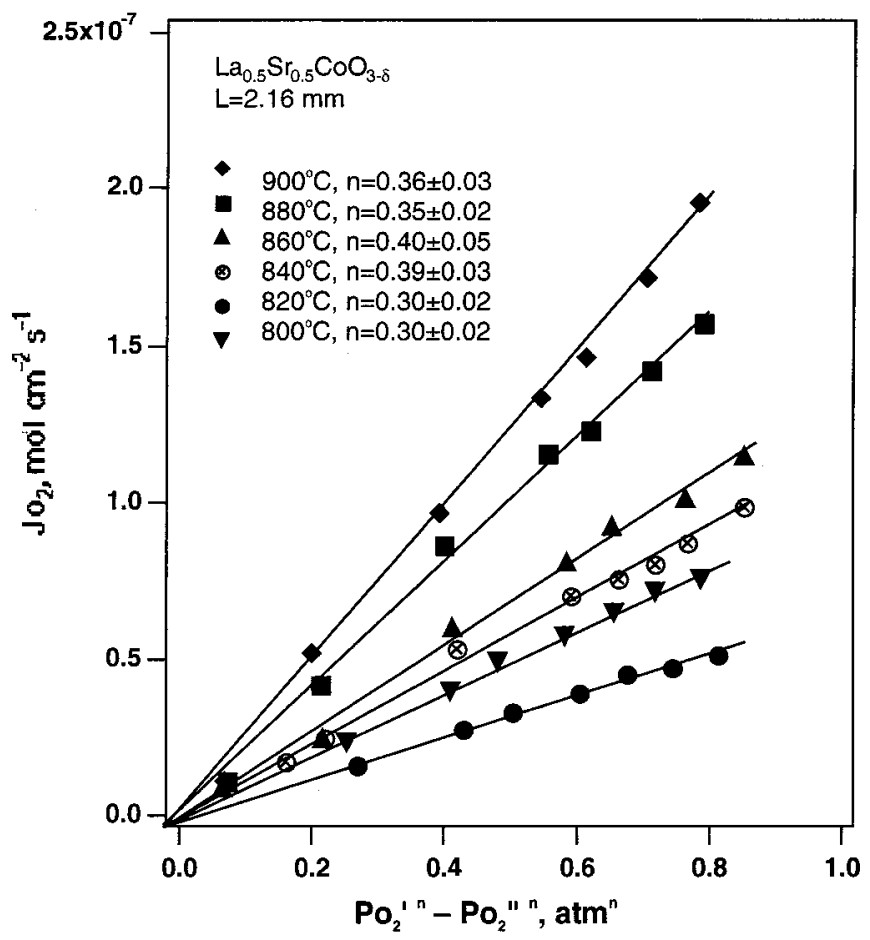

Figure 9. Power law dependence of $J_{\mathrm{O}_{2}}$ on the partial pressure of oxygen for $\mathrm{La}_{0.5} \mathrm{Sr}_{0.5} \mathrm{CoO}_{3-\delta}$ in the case of varied $p_{\mathrm{O}_{2}}^{\prime}$ and $p_{\mathrm{O}_{2}}^{\prime \prime}$. 


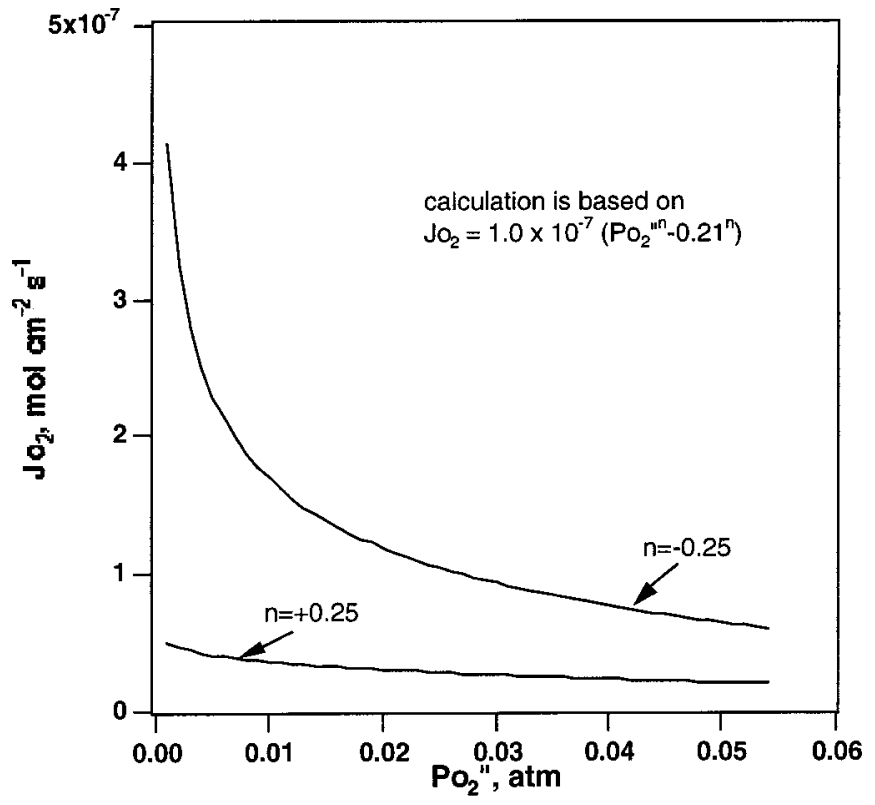

Figure 10. Calculated dependence of $J_{\mathrm{O}_{2}}$ on $p_{\mathrm{O}_{2}}^{\prime \prime}$ with positive and negative values of $n$ in the relationship $J_{\mathrm{O}_{2}}=1.0 \times 10^{-7}\left(p_{\mathrm{O}_{2}}^{\prime \prime \mathrm{n}}-0.21^{\mathrm{n}}\right)$.

exchange kinetics so that the bulk oxygen diffusion dominates the overall permeation process, thus allowing the bulk transport properties of MIECs to be evaluated. With the assumption of a power law relation between $J_{\mathrm{O}_{2}}$ and $p_{\mathrm{O}_{2}}$, the dependence of $J_{\mathrm{O}_{2}}$ on $p_{\mathrm{O}_{2}}^{\prime \prime}$ shown in Fig. 10 was calculated. Clearly, the $J_{\mathrm{O}_{2}}$ exhibits a more remarkable increase at lower $p_{\mathrm{O}_{2}}$ with a negative value of $n$ than that with a positive value of $n$. This observation, in turn, implies a permeation process dominated by bulk oxygen diffusion, provided a sharp increase of $J_{\mathrm{O}_{2}}$ is found at low $p_{\mathrm{O}_{2}}$. Representative plots at $810^{\circ} \mathrm{C}$ of measured $J_{\mathrm{O}_{2}}$ vs. $p_{\mathrm{O}_{2}}^{\prime \prime}$ with an SCF coating on the feeding-gas side,

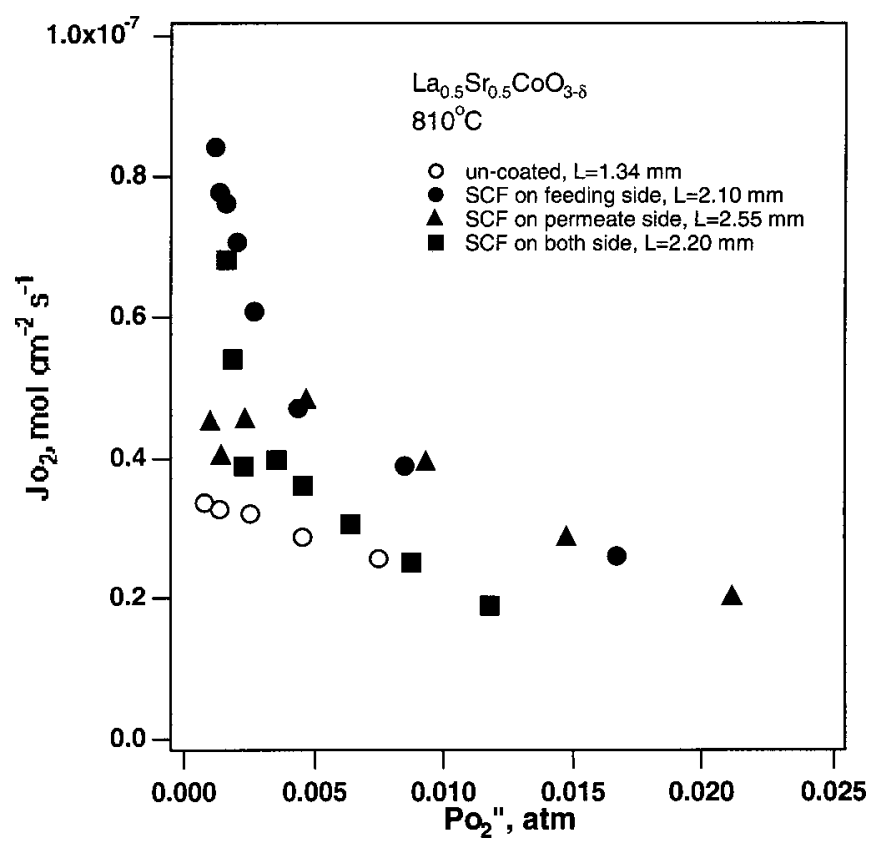

Figure 11. Measured dependence of $J_{\mathrm{O}_{2}}$ on $p_{\mathrm{O}_{2}}^{\prime \prime}$ at $810^{\circ} \mathrm{C}$ for uncoated and SCF-coated $\mathrm{La}_{0.5} \mathrm{Sr}_{0.5} \mathrm{CoO}_{3-\delta}$.

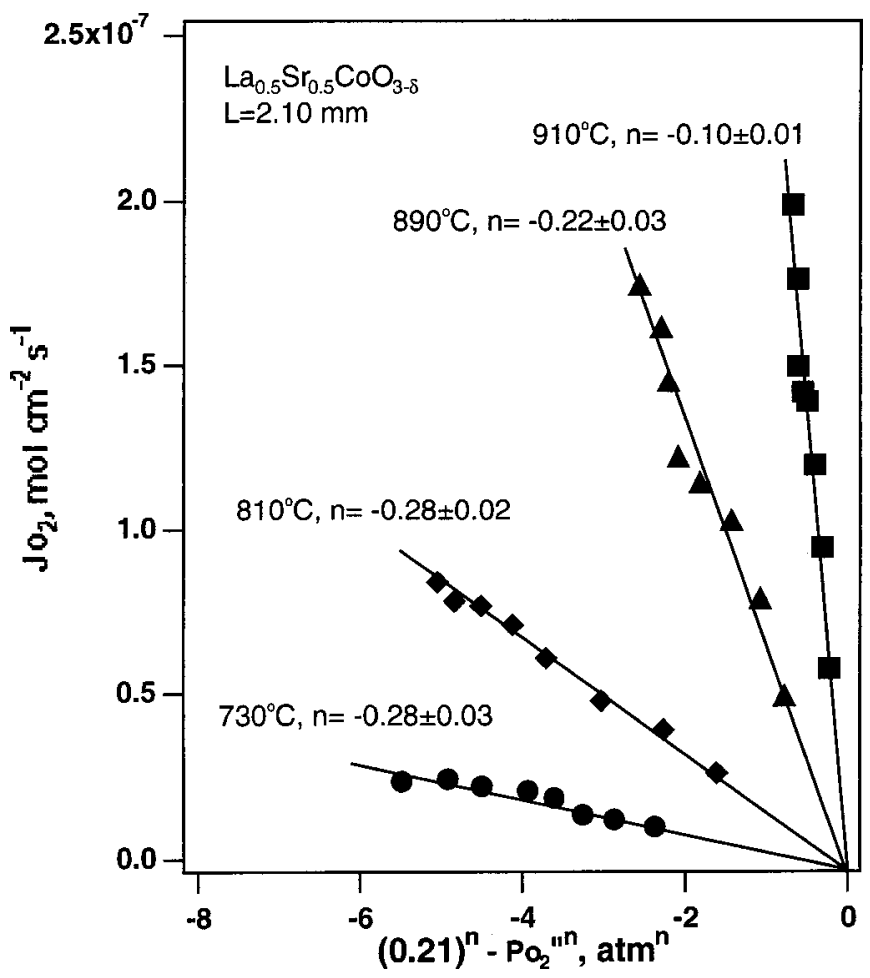

Figure 12. Power law dependence of $J_{\mathrm{O}_{2}}$ on the partial pressure of oxygen for $\mathrm{La}_{0.5} \mathrm{Sr}_{0.5} \mathrm{CoO}_{3-\delta}$ with an SCF coating on the feeding-gas side. The $p_{\mathrm{O}_{2}}^{\prime}$ at the feeding-gas side was kept constant at $0.21 \mathrm{~atm}$.

sweeping-gas side, and both sides, respectively, are shown in Fig. 11; they are compared to the one obtained without an SCF coating. With a coating on the feeding-gas side, the curve exhibits a very similar shape to that shown in Fig. 10 for $n<0$, whereas the $J_{\mathrm{O}_{2}}$ without an SCF coating has a fairly flat change with $p_{\mathrm{O}_{2}}^{\prime \prime}$. A plot of $J_{\mathrm{O}_{2}}$ vs. $p_{\mathrm{O}_{2}}^{\prime \mathrm{n}}-p_{\mathrm{O}_{2}}^{\prime \prime \mathrm{n}}$, shown in Fig. 12, indeed revealed straight lines with negative values of $n$ at various temperatures. All these observations indicate a changeover of the permeation rate from domination by surface exchange to bulk diffusion after an SCF coating was added on the feeding-gas side at a $p_{\mathrm{O}_{2}}^{\prime}=0.21 \mathrm{~atm}$. However, the curve obtained with an SCF coating on the permeate side, shown in Fig. 11, gives a different trend; a plateau of $J_{\mathrm{O}_{2}}$ occurs below a certain lower $p_{\mathrm{O}_{2}}^{\prime \prime}$. Attempts to plot $J_{\mathrm{O}_{2}} v s$. $p_{\mathrm{O}_{2}}^{\prime n}-p_{\mathrm{O}_{2}}^{\prime \prime n}$ for an SCF coating at the permeation side gave a linear relation with negative values of $n$ at higher $p_{\mathrm{O}_{2}}^{\prime \prime}$, but a small plateau at lower $p_{\mathrm{O}_{2}}^{\prime \prime}$. Previous studies ${ }^{20,28}$ have shown that the brownmillerite phase $\mathrm{Sr}_{2} \mathrm{Co}_{2} \mathrm{O}_{5}{ }^{\mathrm{c}}$ is favored at lower temperatures and lower partial pressure of oxygen. Therefore, it is reasonable to believe that the small plateau shown in Fig. 11 is caused by the formation of the poorly conducting brownmillerite phase. The curve for an SCF coating on both sides appears, reasonably, to be a combination of the above two situations. A rapid increase of $J_{\mathrm{O}_{2}}$ after a plateau is observed.

The $J_{\mathrm{O}_{2}}$ as a function of the gradient of the partial pressure of oxygen $(1 / L) \log \left(p_{\mathrm{O}_{2}}^{\prime \prime} / 0.21\right)$ at a given temperature, where $L$ is the thickness of the membrane, is plotted in Fig. 13 for SCF-coated and uncoated samples. Comparison of the 890 and $810^{\circ} \mathrm{C}$ curves of Fig. $13 \mathrm{a}$ and $\mathrm{b}$ shows that the $J_{\mathrm{O}_{2}}$ of the SCF-coated samples has been enhanced at both higher and lower temperatures compared to that of the uncoated one. The enhancement is not only a function of tem-

\footnotetext{
${ }^{\mathrm{c}}$ Note that the brownmillerite phase could also be $\mathrm{Sr}_{2} \mathrm{Co}_{2-x} \mathrm{Fe}_{x} \mathrm{O}_{5}$, according to
} Ref. 21. 

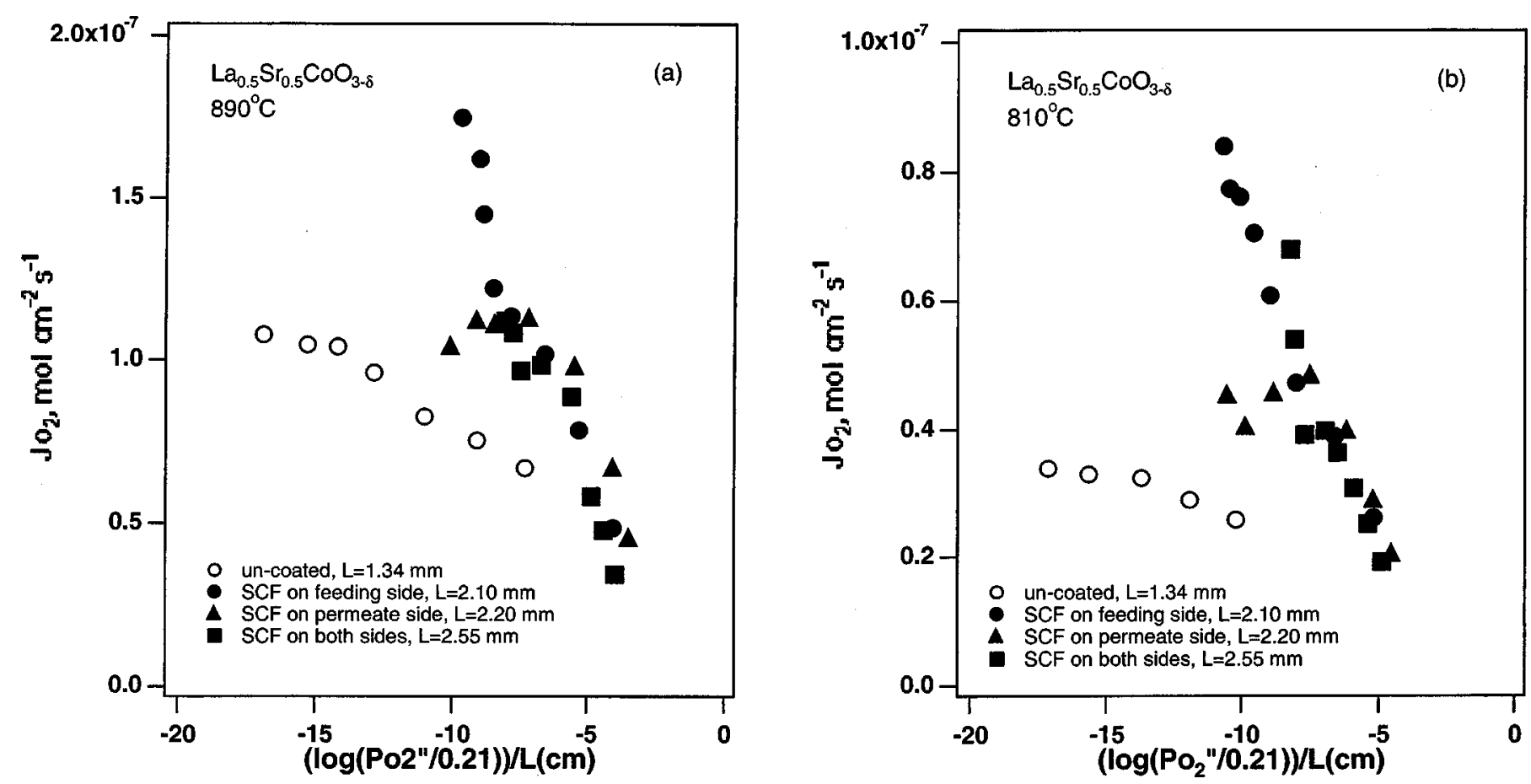

Figure 13. Dependence of $J_{\mathrm{O}_{2}}$ on the gradient of partial pressure of oxygen for uncoated and SCF-coated $\mathrm{La}_{0.5} \mathrm{Sr}_{0.5} \mathrm{CoO}_{3-\delta}$. The $p_{\mathrm{O}_{2}}^{\prime}=0.21$ atm was kept constant; (a) $890^{\circ} \mathrm{C}$, (b) $810^{\circ} \mathrm{C}$.

perature, but is also dependent on the gradient of the partial pressure of oxygen. At a small oxygen gradient or high $p_{\mathrm{O}_{2}}^{\prime \prime}$ range, the SCF coating appears to be less effective than at a large gradient or low $p_{\mathrm{O}_{2}}^{\prime \prime}$ range. This may be due to a slower bulk diffusion at a smaller $p_{\mathrm{O}_{2}}$ gradient. However, a slightly higher $J_{\mathrm{O}_{2}}$ with SCF coated on the permeate side at a small oxygen gradient (see Fig. 13a, b) indicates that the generation of oxygen vacancies at the permeate side is enhanced to a limited extent. With decreasing $p_{\mathrm{O}_{2}}^{\prime \prime}$ at the permeate side (by increasing the flow rate of the sweeping helium gas), the SCF coating on the feeding-gas side gains effectiveness in increasing the $J_{\mathrm{O}_{2}}$, whereas the SCF at the permeate side has no effect, primarily due to the formation of the brownmillerite phase. The SCF coatings have a more pronounced effect at lower temperatures than at higher temperatures. This observation confirms the statement that the sur-

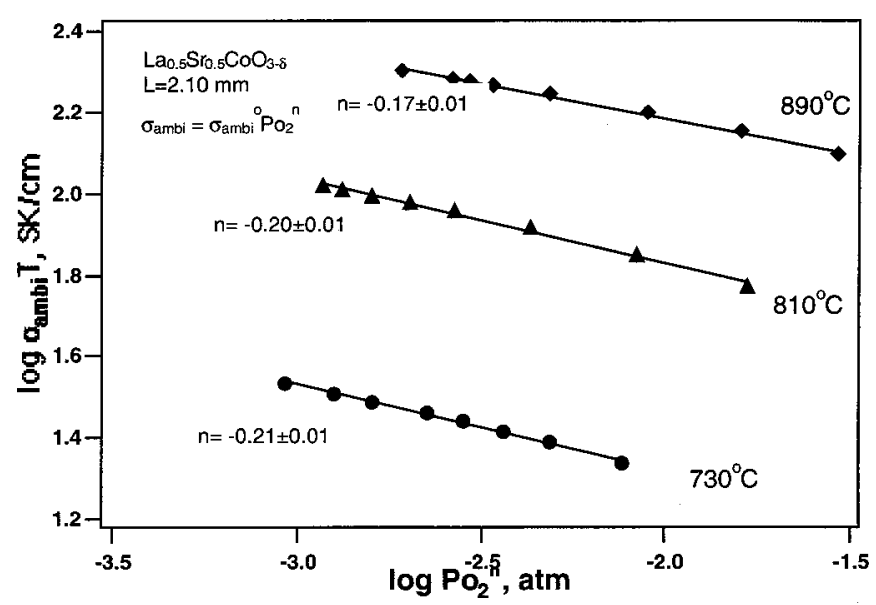

Figure 14. Logarithmic dependence of the ambipolar conductivity of $\mathrm{La}_{0.5} \mathrm{Sr}_{0.5} \mathrm{CoO}_{3-\delta}$ on the partial pressure of oxygen at various temperatures. face oxygen exchange kinetics is slower at lower temperatures than at higher temperatures. In other words, the surface oxygen exchange kinetics requires a higher activation energy than oxygen bulk diffusion.

The changeover of control of permeation rates to bulk oxygen diffusion allows one to calculate the oxide-ion conductivity of a MIEC from the permeation data by differentiating the Wagner equation (Eq. 1) into the following form

$$
\sigma_{\text {ambi }}=-\frac{16 F^{2} L}{2.303 R T}\left(\frac{\partial J_{\mathrm{O}_{2}}}{\partial \log p_{\mathrm{O}_{2}}^{\prime \prime}}\right)_{p_{\mathrm{O}_{2}}^{\prime}=0.21}
$$

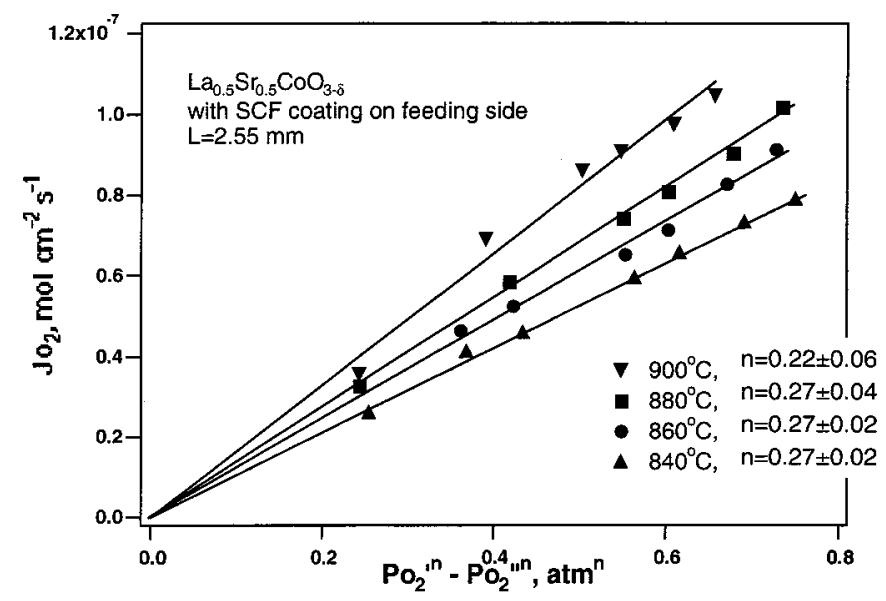

Figure 15. Power law dependence of $J_{\mathrm{O}_{2}}$ on the partial pressure of oxygen for $\mathrm{La}_{0.5} \mathrm{Sr}_{0.5} \mathrm{CoO}_{3-\delta}$ with an $\mathrm{SCF}$ coating on the feeding-gas side in the case of varied $p_{\mathrm{O}_{2}}^{\prime}$ and $p_{\mathrm{O}_{2}}^{\prime \prime}$. 


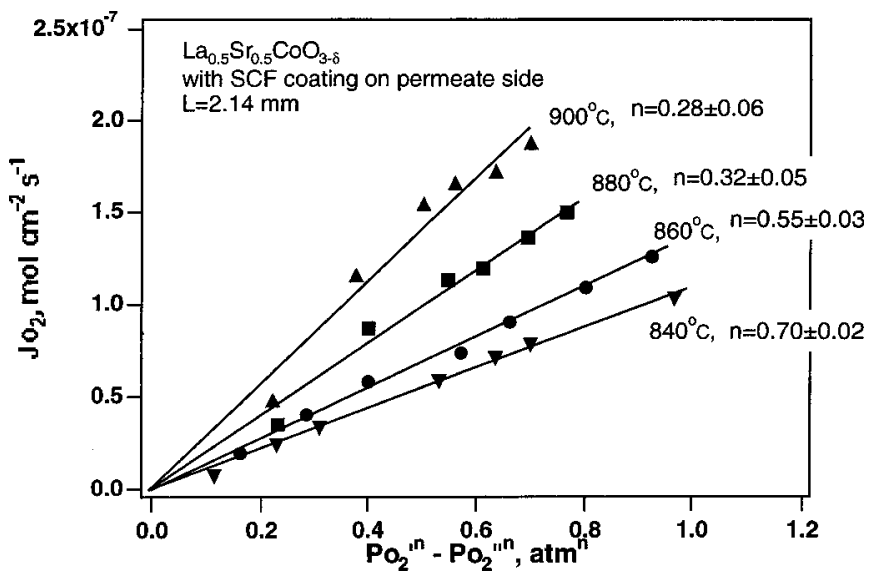

Figure 16. Power law dependence of $J_{\mathrm{O}_{2}}$ on the partial pressure of oxygen for $\mathrm{La}_{0.5} \mathrm{Sr}_{0.5} \mathrm{CoO}_{3-\delta}$ with an SCF coating on the permeate side in the case of varied $p_{\mathrm{O}_{2}}^{\prime}$ and $p_{\mathrm{O}_{2}}^{\prime \prime}$.

where $\sigma_{\text {ambi }} \approx \sigma_{\mathrm{O}}$ as the electronic transport number $t_{\mathrm{e}}$ is far greater than that of the oxide-ion $t_{\mathrm{O}}$ in this study. Figure 14 shows the logarithmic dependence of the calculated ambipolar conductivity on the partial pressure of oxygen at different temperatures from the fitted relationship between $J_{\mathrm{O}_{2}}$ and $\log \left(p_{\mathrm{O}_{2}}^{\prime \prime}\right)$. The increased oxygen vacancy concentration with decreasing partial pressure of oxygen leads to an increase of the ambipolar conductivity in an MIEC. The power index ranges from -0.17 at $890^{\circ} \mathrm{C}$ to -0.21 at $730^{\circ} \mathrm{C}$, which is reasonably between the $-1 / 6$ to $-1 / 4$ predicted from the defect model. The activation energy $E_{\mathrm{a}}=1.25 \mathrm{eV}$ for the ambipolar conduction was obtained from the Arrhenius plot of the $J_{\mathrm{O}_{2}}$.

$J_{\mathrm{O}_{2}}$ under varied $p_{\mathrm{O}_{2}}^{\prime}$ and fixed sweeping-gas flow rate.-The same permeation cell configurations were used for the measurement of $J_{\mathrm{O}_{2}}$ vs. varied $p_{\mathrm{O}_{2}}^{\prime}$ and $p_{\mathrm{O}_{2}}^{\prime \prime}$. The results are strikingly contrary to those discussed in the section on $J_{\mathrm{O}_{2}}$ under $p_{\mathrm{O}_{2}}^{\prime}=0.21$ atm and varied $p_{\mathrm{O}_{2}}^{\prime \prime}$. Figure 15 clearly shows little change of $n$ from Fig. 9 after a surface catalytic layer of SCF was applied on the feeding-gas side. The value of $n, 0<n<0.5$, obtained from the nonlinear leastsquares fitting remained essentially the same within the range of $840^{\circ} \mathrm{C} \leqslant T \leqslant 900^{\circ} \mathrm{C}$. Compared to the sample of Fig. 9 where no SCF coating was applied, the $n$ value is smaller even though the

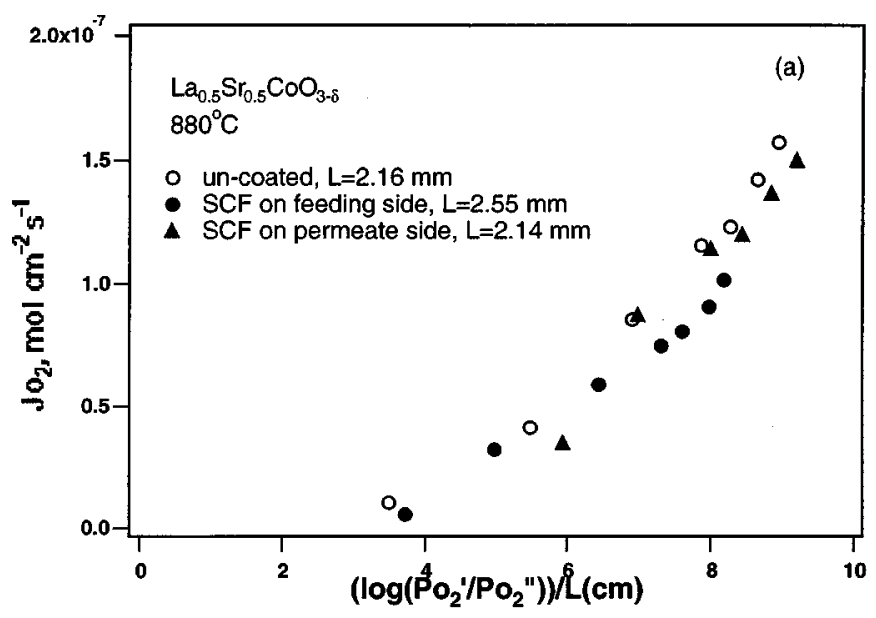

sample of Fig. 9 has a larger membrane thickness. The coating has some catalytic effect on the surface oxygen exchange on the feeding-gas side at lower temperature (see Fig. 17b). However, it is not so effective as to allow the bulk oxygen diffusion to be the slowest step in the overall serial permeation process since a slow surface reaction due to a relatively low flow rate on the permeate side persisted in dominating the permeation. A positive value of $n$ was also observed with an SCF coating on the permeate side (see Fig. 16), but a significant increase of $n$ values from $0<n<0.5$ to a $0.5<n<1$ was found below $860^{\circ} \mathrm{C}$. These results indicate that the SCF on the permeate side has little catalytic effect and, in fact, lowers the permeation rate below $860^{\circ} \mathrm{C}$ because of formation of the brownmillerite phase at lower $p_{\mathrm{O}_{2}}^{\prime \prime}$. This observation is consistent with the measurement in the preceding section showing that the SCF layer on the permeate side does not effectively increase the exchange kinetics on that surface due to brownmillerite formation.

Comparisons of $J_{\mathrm{O}_{2}}$ for SCF-coated and uncoated samples as a function of $(1 / L) \log \left(p_{\mathrm{O}_{2}}^{\prime \prime} / p_{\mathrm{O}_{2}}^{\prime}\right)$ at a given temperature are shown in Fig. 17. At $880^{\circ} \mathrm{C}$, Fig. $17 \mathrm{a}$, no catalytic effect was observed with SCF coatings over the entire oxygen gradient range. However, with the temperature lowered to $840^{\circ} \mathrm{C}$, Fig. $17 \mathrm{~b}$, the $J_{\mathrm{O}_{2}}$ for a sample with SCF coated on the feeding-gas side is higher than that for the uncoated sample. This observation again confirms that surface oxygen exchange kinetics is slower at lower temperatures. The SCF coating on the permeate side appears to have less influence on the $J_{\mathrm{O}_{2}}$ as a result of forming the brownmillerite phase. The $J_{\mathrm{O}_{2}}$ at $840^{\circ} \mathrm{C}$ is lower than that of the uncoated sample at a low feeding-gas $p_{\mathrm{O}_{2}}^{\prime}$ range; it rapidly approaches the same value as that of the uncoated sample at higher $p_{\mathrm{O}_{2}}^{\prime}$, where a higher $p_{\mathrm{O}_{2}}^{\prime \prime}$ can be achieved.

From the results of SCF coating at the permeate side shown in these last two sections, it is clear that the formation of a brownmillerite phase at lower $p_{\mathrm{O}_{2}}^{\prime \prime}$ makes an SCF coating ineffective as a catalyst.

Mechanisms for both surface oxygen exchange and bulk oxygen diffusion control.-A similar study concerning both surface reaction and bulk diffusion associated with the semipermeability of the calcia-doped zirconia was demonstrated by Dou et al. ${ }^{27}$ Unlike pure oxide-ion electrolytes, it is more complicated for mixed electronic and oxide-ion conductors because both oxygen vacancy and hole concentrations could depend on the partial pressures of oxygen. Therefore, the obtained analytic expressions can only be resolved by numerical calculations if no assumptions are made to simplify them. According to the power index $0.5>n>0$ obtained for the

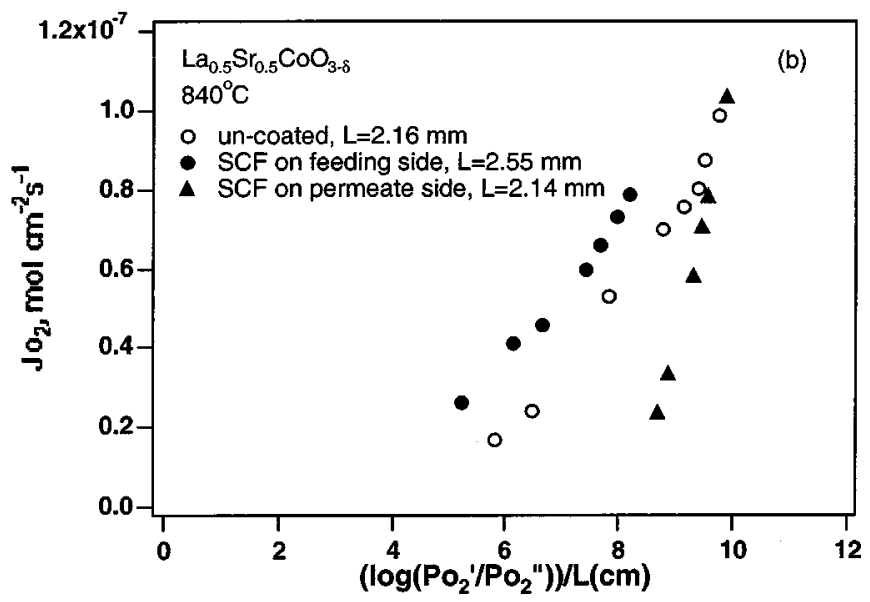

Figure 17. Dependence of $J_{\mathrm{O}_{2}}$ on the gradient of partial pressure of oxygen for uncoated and SCF-coated $\mathrm{La}_{0.5} \mathrm{Sr}_{0.5} \mathrm{CoO}_{3-\delta}$. The $p_{\mathrm{O}_{2}}^{\prime}$ and $p_{\mathrm{O}_{2}}^{\prime \prime}$ were both varied; (a) $880^{\circ} \mathrm{C}$, (b) $840^{\circ} \mathrm{C}$. 
$\mathrm{La}_{1-x} \mathrm{Sr}_{x} \mathrm{CoO}_{3-\delta}$ system, we propose the following mechanism to illustrate the overall permeation process (Kröger-Vink notation is used)

$$
\mathrm{O}_{2\left(\mathrm{~g}^{\prime}\right)}+2 \mathrm{Co}_{\mathrm{Co}\left(\mathrm{s}^{\prime}\right)}^{\times}+\mathrm{V}_{\mathrm{O} \cdot\left(\mathrm{s}^{\prime}\right)} \underset{k_{-3 \mathrm{a}}}{\stackrel{k_{3 \mathrm{a}}}{\rightleftharpoons}}\left(\mathrm{O}_{2}\right)_{\mathrm{O}\left(\mathrm{s}^{\prime}\right)}^{x}+2 \mathrm{Co}_{\mathrm{Co}\left(\mathrm{s}^{\prime}\right)}^{\cdot}
$$

or

$$
\begin{aligned}
& \frac{1}{2} \mathrm{O}_{2\left(\mathrm{~g}^{\prime}\right)}+\mathrm{O}_{\mathrm{o}}^{x} \underset{k_{-3 \mathrm{~b}}}{\stackrel{k_{3 \mathrm{~b}}}{\rightleftharpoons}}\left(\mathrm{O}_{2}\right)_{\mathrm{o}\left(\mathrm{s}^{\prime}\right)}^{x} \\
& \left(\mathrm{O}_{2}\right)_{\mathrm{o}\left(\mathrm{s}^{\prime}\right)}^{x}+2 \mathrm{Co}_{\mathrm{Co}\left(\mathrm{s}^{\prime}\right)}^{\times}+\mathrm{V}_{\mathrm{O}^{*}\left(\mathrm{~s}^{\prime}\right)} \underset{k_{-4}}{\stackrel{k_{4}}{\rightleftharpoons}} 2 \mathrm{Co}_{\mathrm{Co}\left(\mathrm{s}^{\prime}\right)}^{\cdot}+2 \mathrm{O}_{\mathrm{o}\left(\mathrm{s}^{\prime}\right)}^{x} \\
& \mathrm{O}_{\mathrm{o}\left(\mathrm{s}^{\prime}\right)}^{x} \underset{k_{-5}}{\stackrel{k_{5}}{\rightleftharpoons}} \mathrm{O}_{\mathrm{o}\left(\mathrm{s}^{\prime \prime}\right)}^{x} \\
& \mathrm{Co}_{\mathrm{Co}\left(\mathrm{s}^{\prime}\right)} \underset{k_{-6}}{\stackrel{k_{6}}{\rightleftharpoons}} \mathrm{Co}_{\mathrm{Co}\left(\mathrm{s}^{\prime \prime}\right)}^{\cdot} \\
& 2 \mathrm{Co}_{\mathrm{Co}\left(\mathrm{s}^{\prime \prime}\right)}^{\cdot}+2 \mathrm{O}_{\mathrm{o}\left(\mathrm{s}^{\prime \prime}\right)}^{\times} \underset{k_{-7}}{\stackrel{k_{7}}{\rightleftharpoons}}\left(\mathrm{O}_{2}^{\cdot}\right)_{\mathrm{o}\left(\mathrm{s}^{\prime \prime}\right)}^{x}+2 \mathrm{Co}_{\mathrm{Co}\left(\mathrm{s}^{\prime \prime}\right)}^{\times}+\mathrm{V}_{\mathrm{O} \cdot\left(\mathrm{s}^{\prime \prime}\right)} \\
& \left(\mathrm{O}_{2}\right)_{\mathrm{O}\left(\mathrm{s}^{\prime \prime}\right)}^{x}+2 \mathrm{Co}_{\mathrm{Co}\left(\mathrm{s}^{\prime \prime}\right)}^{\cdot} \underset{k_{-8 \mathrm{a}}}{\stackrel{k_{8 \mathrm{a}}}{\rightleftharpoons}} \mathrm{O}_{2\left(\mathrm{~g}^{\prime \prime}\right)}+2 \mathrm{Co}_{\mathrm{Co}\left(\mathrm{s}^{\prime \prime}\right)}^{\times}+2 \mathrm{~V}_{\mathrm{O} \cdot\left(\mathrm{s}^{\prime \prime}\right)}
\end{aligned}
$$

or

$$
\left(\mathrm{O}_{2}\right)_{\mathrm{O}\left(\mathrm{s}^{\prime \prime}\right)}^{\times} \underset{k_{-8 \mathrm{~b}}}{\stackrel{k_{8 \mathrm{~b}}}{\rightleftharpoons}} \frac{1}{2} \mathrm{O}_{2\left(\mathrm{~g}^{\prime \prime}\right)}+\mathrm{O}_{\mathrm{o}\left(\mathrm{s}^{\prime \prime}\right)}^{x}
$$

In the above reactions, $k_{\mathrm{i}}$ and $k_{-\mathrm{i}}$ are the rate constants of the forward and reverse reactions, respectively. By the Kröger-Vink notation, $\mathrm{O}_{\mathrm{o}}{ }^{\times}$and $\mathrm{V}_{\mathrm{O}}$.* are a lattice oxygen and an oxygen vacancy, respectively; $\mathrm{Co}_{\mathrm{Co}}^{\times}$and $\mathrm{Co}_{\mathrm{Co}} \cdot$ are $3+$ and $4+\mathrm{Co}$ ions, respectively; $\left(\mathrm{O}_{2}\right)_{0}^{\times}$represents the peroxide ion on the oxygen site; and s' and s" denote the surfaces at the feeding-gas side and that at the sweepinggas side, respectively. Reactions $3 \mathrm{~b}$ and $8 \mathrm{~b}$ represent the adsorption and desorption of gaseous oxygen to form and to dissociate the peroxide ions on the surface. Many studies have shown the existence of the peroxide ion on the surface of oxides by X-ray photoemission spectroscopy. Reactions 4 and 7 illustrate the annihilation and production of oxygen vacancies that are charge-compensated by electronic holes and electrons, respectively. Over the whole process, we assume that Reactions $3 \mathrm{~b}$ and $8 \mathrm{~b}$ as well as electronic transport (Reaction 6) are rapid and at their equilibrium. The rate-determining steps are therefore the transport of surface oxygen atoms to oxygen vacancies (Reaction 4), the production of oxygen vacancies (Reaction 7), and bulk oxygen vacancy diffusion (Reaction 5), dressed by two electrons.

The detailed formulation of the above processes is not given, for conciseness, but the finalized expression is introduced as follows

$$
\begin{gathered}
J_{\mathrm{O}_{2}}=\frac{D_{\mathrm{O}} K_{3 \mathrm{~b}} K_{4}}{2 L}\left[\mathrm{Co}_{\mathrm{Co}}^{\times}\right] \frac{\delta^{\mathrm{o}}}{p^{\mathrm{o}}}\left(p_{\mathrm{O}_{2}}^{\prime 0.5-\mathrm{m}-2 \mathrm{r}}-p_{\mathrm{O}_{2}}^{\prime \prime 0.5-\mathrm{m}-2 \mathrm{r}}\right) \\
{\left[\mathrm{V}_{\mathrm{O}^{* *}\left(s^{\prime}\right)}\right]=\delta^{\mathrm{o}} p_{\mathrm{O}_{2}}^{\prime-\mathrm{m}}\left[\mathrm{V}_{\mathrm{O}^{* *}\left(\mathrm{~s}^{\prime \prime}\right)}\right]=\delta^{\mathrm{o}} p_{\mathrm{O}_{2}}^{\prime \prime-\mathrm{m}} \quad(m>0)} \\
{\left[\mathrm{Co}_{\mathrm{Co}\left(\mathrm{s}^{\prime}\right)}^{\cdot}\right]=p^{\mathrm{o}} p_{\mathrm{O}_{2}}^{\prime \mathrm{r}}\left[\mathrm{Co}_{\mathrm{Co}\left(\mathrm{s}^{\prime \prime}\right)}^{\cdot}\right]=p^{\mathrm{o}} p_{\mathrm{O}_{2}}^{\prime \prime \mathrm{r}} \quad(r>0)} \\
{\left[\mathrm{Co}_{\mathrm{Co}}^{\times}\right] \approx\left[\mathrm{Co}_{\mathrm{Co}\left(\mathrm{s}^{\prime}\right)}^{\times}\right] \approx\left[\mathrm{Co}_{\mathrm{Co}\left(\mathrm{s}^{\prime \prime}\right)}^{\times}\right] \approx 1}
\end{gathered}
$$

where $D_{\mathrm{O}}$ is the is the oxygen vacancy diffusivity, $L$ is the thickness of the membrane, [defect] represents the concentration of the defect, $\delta^{\circ}$ and $p^{\circ}$ are the constants, and $K_{3 \mathrm{~b}}$ and $K_{4}$ represent the equilibrium constants of Reactions 3 and 4, respectively.

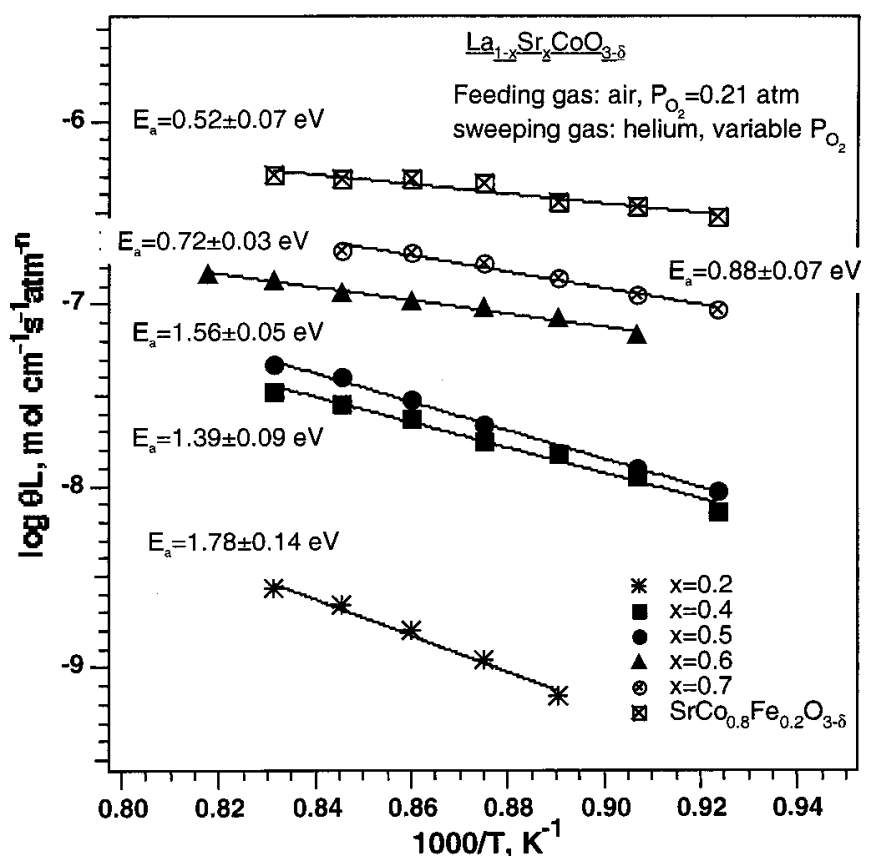

Figure 18. Arrhenius plot of $\log \theta L$ for all uncoated compositions investigated in this study.

For a similar sample thickness at which both surface exchange and bulk diffusion control the permeation, various Sr doping levels could lead to a systematic change of the value of $n$. Generally, at a lower doping level $x$, the nonstoichiometry of oxygen is very low, and the electrical neutrality condition may be simplified into $p$ $\approx x$, in which case $n=0.5-m$ in Eq. 9. At a higher Sr doping $x$, the nonstoichiometry of oxygen could be fixed by Sr doping, and the electrical neutrality condition can be simplified to $\delta=x / 2$, and $n=0.5-2 r$ in Eq. 9. At intermediate doping, a minimum of $n=0.5-m-2 r$ can be expected. The experimental data in Table III confirm such a prediction.

For the $\mathrm{SrCo}_{0.8} \mathrm{Fe}_{0.2} \mathrm{O}_{3-\delta}$ sample, the $1>n>0.5$ shown in Table III appears to imply a different rate-limiting step at the surfaces. We notice that $\mathrm{Fe}$ may play a decisive role in the surface reaction since a surface $\mathrm{Fe}^{3+}$ ion is stable in tetrahedral coordination. As in Reaction 3a, gaseous oxygen occupies the site of an oxygen vacancy on the surface to become a surface peroxide ion. However, at an $\mathrm{Fe}^{3+}$ ion, transformation from tetrahedral to octahedral oxygen coordination allows the gaseous $\mathrm{O}_{2}$ to become $2 \mathrm{O}^{2-}$ without surface diffusion of oxygen to a vacancy at another cation. Therefore, Reactions 3a and 8a become rate limiting. The oxygen flux $J_{\mathrm{O}_{2}}$ is given in the following equation

$$
\begin{gathered}
J_{\mathrm{O}_{2}}=\varepsilon\left(p_{\mathrm{O}_{2}}^{\prime 1-\mathrm{m}}-p_{\mathrm{O}_{2}}^{\prime \prime-\mathrm{m}}\right) \quad(m>0) \\
\varepsilon=\frac{1}{2} k_{-3 \mathrm{a}}\left[\mathrm{Co}_{\mathrm{Co}}^{\times}\right] \delta^{\mathrm{o}}
\end{gathered}
$$

where the power index $n=1-m$ is obtained. $k_{-3 \text { a }}$ represents the rate constant of the reverse reaction (Reaction $3 \mathrm{a}$ ). This prediction agrees well with the experimental data shown in Table III.

According to Eq. 9, $\log \theta L$ vs. $1 / T$ should give a straight line with a slope associated with the apparent activation energy $E_{\mathrm{a}}$ of the permeation process, where $\theta$ represents the slope of the straight line obtained by plotting $J_{\mathrm{O}_{2}}$ vs. $p_{\mathrm{O}_{2}}^{\prime \mathrm{n}}-p_{\mathrm{O}_{2}}^{\prime \prime n}$. Figure 18 presents such a 
plot for all compositions studied as indicated by Eq. 9. The shown activation energies $E_{\mathrm{a}}$ exhibit a general decrease with $\mathrm{Sr}$ doping level $x$. If $E_{\mathrm{a}}$ for $x=0.20$ represents the bulk diffusion, the highest $E_{\mathrm{a}}$ signals an unfavorable migration environment due to the presence of two electronic phases. ${ }^{25}$ However, with increasing doping level $x$, both structure and oxygen vacancy concentration begin to favor high oxygen conductivity, which changes the rate-limiting step from bulk diffusion to surface exchange. Provided that surface exchange does not change very much with composition, the significant decrease of activation energy $E_{\mathrm{a}}$ must be attributed to the change of the structure and oxygen vacancy concentration. It is clear that cubic symmetry that leads to a linear configuration of the Co$\mathrm{O}-\mathrm{Co}$ bonds in the perovskite is the best structure for having the highest oxide-ion mobility. In the rhombohedral structure, the Co-O bonds are under compression. In the cubic structure, the Co-O bonds are under tension, and the tension increases with temperature because of the larger thermal expansion of the A-O bonds of an $\mathrm{ACoO}_{3}$ perovskite where there is no low-spin to intermediate-spin transition on the $\mathrm{Co}(\mathrm{III})$. Comparison of $\mathrm{La}_{1-x} \mathrm{Sr}_{x} \mathrm{CoO}_{3-\delta}$ and $\mathrm{SrCo}_{0.8} \mathrm{Fe}_{0.2} \mathrm{O}_{3-\delta}$ illustrates a trend to lower activation energy as the stress on the $\mathrm{Co}-\mathrm{O}$ bond changes.

\section{Conclusions}

The oxygen flux $J_{\mathrm{O}_{2}}$ across two ceramic membranes, $\mathrm{SrCo}_{0.8} \mathrm{Fe}_{0.2} \mathrm{O}_{3-\delta}$ and $\mathrm{La}_{0.5} \mathrm{Sr}_{0.5} \mathrm{CoO}_{3-\delta}$ as a representative of the $\mathrm{La}_{1-x} \mathrm{Sr}_{x} \mathrm{CoO}_{3-\delta}$ system, were systematically studied as a function of temperature, the gradient of oxygen chemical potential, and thickness. The gradient of oxygen partial pressure across a membrane was varied either by changing the $p_{\mathrm{O}_{2}}^{\prime \prime}$ at the permeate side with a fixed $p_{\mathrm{O}_{2}}^{\prime}=0.21 \mathrm{~atm}$ at the feeding-gas side or by changing the feeding-gas $p_{\mathrm{O}_{2}}^{\prime}$ while keeping constant the flow rate of a helium sweeping gas at the permeate side. The influence of a catalytically active surface layer $\mathrm{SrCo}_{0.8} \mathrm{Fe}_{0.2} \mathrm{O}_{3-\delta}$ on the $J_{\mathrm{O}_{2}}$ of $\mathrm{La}_{0.5} \mathrm{Sr}_{0.5} \mathrm{CoO}_{3-\delta}$ was also studied.

The magnitude of $p_{\mathrm{O}_{2}}^{\prime \prime}$ varies as a power of the rate of flow of the helium sweeping gas across the permeate surface, and the power index is independent of temperature. As a consequence, plots of $J_{\mathrm{O}_{2}}$ vs. $\left(p_{\mathrm{O}_{2}}^{\prime \mathrm{n}}-p_{\mathrm{O}_{2}}^{\prime \prime n}\right)$ for a fixed membrane thickness $L$ were straight lines passing through the origin with a slope varying as $L^{-1} \exp \left(-E_{\mathrm{a}} / k T\right)$. The temperature dependence of $J_{\mathrm{O}_{2}}$ under a given $\log \left(p_{\mathrm{O}_{2}}^{\prime} / p_{\mathrm{O}_{2}}^{\prime \prime}\right)$ and $L$ was shown to obey an Arrhenius relation with an activation energy $E_{\mathrm{a}}=1.56 \mathrm{eV}$ for $\mathrm{La}_{0.5} \mathrm{Sr}_{0.5} \mathrm{CoO}_{3-\delta}$ without an active SCF coating, and a positive power index $0.5>n$ $>0$ showed that the oxygen flux across the membrane is controlled partially by the reaction kinetics at the surface. The value of $n$ increased with decreasing membrane thickness toward a predicted 0.5 for surface control. For $\mathrm{SrCo}_{0.8} \mathrm{Fe}_{0.2} \mathrm{O}_{3-\delta}$, the value of $n$ was in the range of $1>n>0.5$, which indicates that a surface reaction different from that on $\mathrm{La}_{0.5} \mathrm{Sr}_{0.5} \mathrm{CoO}_{3-\delta}$ is rate controlling.

With a catalytically active SCF coating, the dependence of $J_{\mathrm{O}_{2}}$ on the gradient of the partial pressure of oxygen and the temperature can be used to determine the rate-limiting steps by comparison with the data for an uncoated sample. At a fixed $p_{\mathrm{O}_{2}}^{\prime}=0.21 \mathrm{~atm}$, the $J_{\mathrm{O}_{2}}$ can be remarkably increased at a lower $p_{\mathrm{O}_{2}}^{\prime \prime}$ with a coat of the SCF on the feeding-gas side. In contrast, an SCF coating on the permeate side has little effect at high $p_{\mathrm{O}_{2}}^{\prime \prime}$ and even a negative effect on $J_{\mathrm{O}_{2}}$ at low $p_{\mathrm{O}_{2}}^{\prime \prime}$ due to the formation of a poorly conducting brownmillerite phase. For a fixed helium flow rate of $20 \mathrm{~mL} / \mathrm{min}$ at the permeate side while changing the $p_{\mathrm{O}_{2}}^{\prime}$ at the feeding side, the SCF coating does not increase $J_{\mathrm{O}_{2}}$ significantly over the entire partial pressure gradient of oxygen measured. In other words, the SCF coating does not enhance the surface reaction as in the case of a fixed $p_{\mathrm{O}_{2}}^{\prime}$
$=0.21 \mathrm{~atm}$ and a varied $p_{\mathrm{O}_{2}}^{\prime \prime}$. The value of $n$ remained positive, indicating surface-involved rate-limiting steps in the permeation process for all $p_{\mathrm{O}_{2}}$ and temperatures. This observation may imply that the gas flowing pattern is important. However, in both cases, the SCF coating evidently increased the $J_{\mathrm{O}_{2}}$ more at lower temperatures than at higher temperatures, which signals that the overall exchange kinetics requires a higher activation energy than that of ambipolar transport across the MIEC.

Another important finding in this study is the changeover of the rate-limiting step from surface or surface-bulk mixed control to a sole bulk control with the aid of an SCF coating on the feeding-gas side. This changeover enabled us to evaluate the bulk properties of the MIEC. The ambipolar conductivity for the $\mathrm{La}_{0.5} \mathrm{Sr}_{0.5} \mathrm{CoO}_{3-\delta}$ follows a power law relationship with $p_{\mathrm{O}_{2}}$; the power index ranges from $n=-0.17$ at $890^{\circ} \mathrm{C}$ to -0.21 at $730^{\circ} \mathrm{C}$. The Arrhenius plot of the ambipolar conductivity gave an activation energy $E_{\mathrm{a}}$ $=1.25 \mathrm{eV}$ under a $p_{\mathrm{O}_{2}}=0.01 \mathrm{~atm}$.

Two mechanistic models were proposed to interpret the observed results in the systems $\mathrm{La}_{1-x} \mathrm{Sr}_{x} \mathrm{CoO}_{3-\delta}$ and $\mathrm{SrCo}_{0.8} \mathrm{Fe}_{0.2} \mathrm{O}_{3-\delta}$. For the $\mathrm{La}_{1-x} \mathrm{Sr}_{x} \mathrm{CoO}_{3-\delta}$ system, the transport of surface oxygen to a vacancy on the feeding-gas surface and the creation of oxygen vacancies on the permeate side are assumed to be the rate-determining steps on the surface, while the step that transports an oxygen vacancy is the rate-determining step in the bulk. Based on this model, an expression $J_{\mathrm{O}_{2}}=\theta\left(p_{\mathrm{O}_{2}}^{\prime \mathrm{n}}-p_{\mathrm{O}_{2}}^{\prime \prime \mathrm{n}}\right)$, where $0.5>n>0$, has been derived. For the $\mathrm{SrCo}_{0.8} \mathrm{Fe}_{0.2} \mathrm{O}_{3-\delta}$ system, a similar expression can be obtained with $1>n>0.5$ by assuming that the chemisorption and desorption of gaseous $\mathrm{O}_{2}$ on the surfaces are the ratedetermining steps. The model agrees well with the experimental results.

\section{Acknowledgments}

The authors thank Robert Welch Foundation for financial support. The authors are grateful to Dr. Schöder for his partial help on the setup of the instrument and Jenh-Haw Wan for helping to make some of the samples.

The University of Texas at Austin assisted in meeting the publication costs of this article.

\section{References}

1. I. Riess, Solid State Ionics, 91, 221 (1996).

2. I. Riess and D. S. Tannhauser, Solid State Ionics, 7, 307 (1982).

3. B. Ma, J.-H. Park, C. U. Segre, and U. Balachandran, Mater. Res. Soc. Symp. Proc., 393, 49 (1997)

4. J. Maier, Solid State Ionics, 112, 197 (1998).

5. R. A. De Souza and J. A. Kilner, Solid State Ionics, 106, 175 (1998); 126, 153 (1999).

6. J. A. Kilner, B. C. H. Steele, and L. Ilkov, Solid State Ionics, 12, 89 (1984).

7. R. J. Chater, S. Carter, J. A. Kilner, and B. C. H. Steele, Solid State Ionics, 53-56, 859 (1992).

8. J. A. Kilner and R. A. De Souza, in High Temperature Electrochemistry: Ceramics and Metals, Proceedings 17th Int. Riso Symp. Mat. Sci., F. W. Poulsen, N. Bonanos, S. Linderoth, M. Morgensen, and B. Zachau-Christiansen, Editors, Roskilde, Denmark, p. 41, 1996.

9. J. A. Kilner, in Proceedings of the Second International Symposium on Ionic amd Mixed Conducting Ceramics, T. A. Ramanarayanan, W. L. Worrell, and H. L. Tuller, Editors, PV 94-12, p. 174, The Electrochemical Society Proceedings Series, Pennington, NJ (1994).

10. C. H. Chen, H. Kruidhof, H. J. M. Bouwmeester, and A. J. Burggraaf, J. Appl. Electrochem., 27, 71 (1997).

11. C. H. Chen, H. J. M. Bouwmeester, R. H. E. van Doorn, H. Kruidhof, and A. J. Burggraaf, Solid State Ionics, 98, 7 (1997).

12. R. H. E. van Doorn, H. Kruidhof, H. J. M. Bouwmeester, and A. J. Burggraaf, Mater. Res. Soc. Symp. Proc., 369, 377 (1995).

13. B. C. H. Steele, Solid State Ionics, 75, 157 (1995).

14. H. J. M. Bouwmeester, H. Kruidhof, and A. J. Burggraaf, Solid State Ionics, 72, 185 (1994).

15. J. A. Kilner, R. A. De Souza, and I. C. Fullarton, Solid State Ionics, 86-88, 703 (1996).

16. A. Bielanski and J. Haber, Oxygen in Catalysis, Marcel Dekker, New York (1991).

17. M. Misono and T. Nitadori, in Adsorption and Catalysis on Oxide Surfaces, M. Che and G. C. Bond, Editors, p. 409, Elsevier, Amsterdam (1985). 
18. M. Pechni, U.S. Pat. 3,330,697 (1967).

19. K. Q. Huang and John B. Goodenough, Solid State Chem., 136, 274 (1998).

20. L. Qiu, T. H. Lee, L. M. Liu, Y. L. Yang, and A. J. Jacobson, Solid State Ionics, 76, 321 (1995).

21. W. T. A. Harrison, T. H. Lee, Y. L. Yang, D. P. Scarfe, L. M. Liu, and A. J. Jacobson, Mater. Res. Bull., 30, 621 (1995).

22. H. Ohbayashi, T. Kudo, and T. Gejo, Jpn. J. Appl. Phys., 13, 1 (1974)

23. J. Mizusaki, Y. Mima, S. Yamauchi, and K. Fueki, Solid State Chem., 80, 102 (1989).
24. A. N. Petrov, V. A. Cherepanov, O. F. Kononchuk, and Ya. Gavrilova, Solid State Chem., 87, 69 (1990).

25. M. A. Senãris-Rodriguez and J. B. Goodenough, J. Solid State Chem., 118, 323 (1995).

26. T. H. Lee, Y. L. Yang, A. J. Jacobson, B. Abeles, and M. Zhou, Solid State Ionics, 100, 77 (1997).

27. S. Dou, C. R. Masson, and P. D. Pacey, J. Electrochem. Soc., 132, 1843 (1985).

28. L. M. Liu, T. H. Lee, L. Qiu, Y. L. Yang, and A. J. Jacobson, Mater. Res. Bull., 31 29 (1996). 